\title{
REVIEW
}

\section{Chromatin reprogramming as an adaptation mechanism in advanced prostate cancer}

\author{
Peder Rustøen Braadland1,2 and Alfonso Urbanucci1,3,4 \\ 1Department of Tumor Biology, Institute for Cancer Research, Oslo University Hospital, Oslo, Norway \\ Institute of Clinical Medicine, University of Oslo, Oslo, Norway \\ ${ }_{3}^{3}$ Institute for Cancer Genetics and Informatics, Oslo University Hospital, Oslo, Norway \\ ${ }^{4}$ Centre for Molecular Medicine Norway, Nordic European Molecular Biology Laboratory Partnership, Forskningsparken, University of Oslo, Oslo, Norway
}

Correspondence should be addressed to A Urbanucci: alfonsourbanucci@gmail.com

\begin{abstract}
Tumor evolution is based on the ability to constantly mutate and activate different pathways under the selective pressure of targeted therapies. Epigenetic alterations including those of the chromatin structure are associated with tumor initiation, progression and drug resistance. Many cancers, including prostate cancer, present enlarged nuclei, and chromatin appears altered and irregular. These phenotypic changes are likely to result from epigenetic dysregulation. High-throughput sequencing applied to bulk samples and now to single cells has made it possible to study these processes in unprecedented detail. It is therefore timely to review the impact of chromatin relaxation and increased DNA accessibility on prostate cancer growth and drug resistance, and their effects on gene expression. In particular, we focus on the contribution of chromatinassociated proteins such as the bromodomain-containing proteins to chromatin relaxation. We discuss the consequence of this for androgen receptor transcriptional activity and briefly summarize wider gain-of-function effects on other oncogenic transcription factors and implications for more effective prostate cancer treatment.
\end{abstract}

\author{
Key Words \\ - castration-resistant prostate \\ cancer \\ - chromatin structure \\ - bromodomain \\ - glucocorticoid receptor \\ - androgen receptor \\ - MYC \\ - histone acetylation \\ - BRD4
}

\section{Introduction}

Prostate cancer (PC) is the most common cancer in North American and European men. Despite the recent decrease in mortality rate in Nordic countries (Kvale et al. 2017), PC represents the second leading cause of cancer-related death in Norway (Center et al. 2012).

Treatment for clinically localized PC tumors mainly involves radical prostatectomy (RP) or radiation therapy. For men with advanced and/or metastatic disease, however, treatments targeting androgen signaling remain the cornerstone intervention strategy. Androgen deprivation therapy (ADT), which lowers patient serum testosterone levels and thereby limits ligand-mediated androgen receptor (AR) activity, is initially effective in most tumors due to their androgen dependence. Unfortunately, ADT is associated with a near inevitable recurrence into castration-resistant prostate cancer (CRPC), which is ultimately lethal. Antiandrogens such as enzalutamide and apalutamide, and drugs targeting hormone synthesis, such as abiraterone, have offered a survival benefit for men with CRPC. Like for ADT, however, resistance towards these drugs is predictable and can manifest as distinct molecular disease subtypes with varying dependency on the AR signaling axis (Bluemn et al. 2017, Culig 2017).

The AR is a transcription factor (TF) that senses androgens levels (McEwan 2004) and mediates essential
C) 2019 Society for Endocrinology Published by Bioscientifica Ltd. Printed in Great Britain 
signaling required for both prostate gland development, maintenance and PC progression (Kim \& Ryan 2012). Upon ligation of androgens, the AR translocates to the nucleus where it binds to specific genomic regions (AR-binding sites (ARBSs)) containing androgen-responsive elements (AREs). This drives the expression of so-called AR target genes. AR target gene transcriptional regulation is associated with extensive chromatin remodeling, which includes alteration of histone modifications (Wang et al. 2018a). The chromatin packs DNA, histones (organized as octamers, collectively forming the nucleosomes) and other chromatin-associated proteins in a dynamic structure within the nucleus of cells. As the chromatin structure dictates the accessibility of the genome, it allows cell-type-specific transcription. Unsurprisingly, chromatin structure regulation contributes greatly to cell differentiation and preservation of cell identity, and chromatin deregulation is associated with many diseases, including PC (Ruggero et al. 2018).

The fact that CRPCs often show clinical responses upon treatments targeting the AR signaling axis indicates that AR activity remains important to sustain growth of these tumors (Rehman \& Rosenberg 2012). Although the emergence of CRPC has been imputed to several mechanisms (reviewed in Waltering et al. 2012, Watson et al. 2015), mechanisms involving the $\mathrm{AR}$ and its signaling axis are considered fundamental. Supporting the importance of AR, large-scale sequencing studies on clinical material has shown that AR is overexpressed or altered in more than 90\% of advanced CRPCs (Taylor et al. 2010, Barbieri et al. 2012, Grasso et al. 2012, Robinson et al. 2015). These studies have also highlighted a plethora of alterations associated with PC progression and therapy resistance, including multiple chromatin- and histonemodifying genes (Barbieri et al. 2012, Grasso et al. 2012, Robinson et al. 2015). Importantly, genomic alterations associated with chromatin remodeling-associated genes are enriched in therapy-resistant tumors (Robinson et al. 2015), suggesting that chromatin remodeling represents an adaptation mechanism that enables PC progression and therapy resistance.

Macroscopically, cancer initiation, including PC oncogenesis, is associated with alterations of the chromatin structure and density. Together with the observation of alterations in the tissue architecture of transformed prostate glands, one of the first major acknowledged criteria for pathological evaluation and diagnosis of PC was the presence of nuclear and nucleolar enlargements observed nearly 70 years ago (Totten et al. 1953). This latter histological feature is still uniformly accepted (Humphrey 2007). In particular, different nuclear morphometric descriptors have been shown to be able to predict occurrence of distant metastasis and death in PC patients with biochemical recurrence after RP (Khan et al. 2003). More recently, visualization of chromatin in tumor cell nuclei by image texture analysis have also been used to predict PC patient outcomes (Hveem et al. 2016, Kleppe et al. 2018).

Aside from imaging techniques, epigenomic assays, such as chromatin immunoprecipitation followed by hybridization to arrays (ChIP-chip), sequencing (ChIPseq) or simply PCR (ChIP-qPCR) (O'Neill \& Turner 1996, Johnson et al. 2007), have been used to analyze chromatin structures. More recent technical advances including formaldehyde-assisted isolation of regulatory elements sequencing (FAIRE-seq) (Song et al. 2011), assay for transposase-accessible chromatin for sequencing (ATAC-seq; Buenrostro et al. 2013), chromatin interaction analysis by paired-end tag sequencing (ChIA-PET) and chromatin conformation capture (3C, 4C and 5C; Fullwood \& Ruan 2009) have opened for a better understanding of higher-order chromatin structural alterations during cancer initiation and progression (Fig. 1). Studies on chromatin structure and dynamics in PC have mainly revolved around understanding the mechanism by which the nuclear testosterone/dihydrotestosterone-ligated AR binds to the chromatin and modulates target gene transcription. Altered chromatin-binding patterns of AR or other TFs, together with alterations of the chromatin structure, are increasingly appreciated as oncogenic drivers also in PC (Sharma et al. 2013, Makova \& Hardison 2015, Stelloo et al. 2015, Urbanucci et al. 2017, Corces et al. 2018, Taipale 2018).

Importantly, the AR cistrome, which is the repertoire of ARBSs within the cells, has been shown to be extensively reprogrammed during PC initiation (Pomerantz et al. 2015) and progression (Sharma et al. 2013). In this context, 'reprogramming' relates to the altered pattern of ARBSs that is different in normal epithelial cells and in PC cells. More generally, the mechanisms by which TF activation, re-activation and reprogramming are occurring in PC are incompletely understood, but considerable evidence point at epigenetic alterations, including changes in the chromatin structure, as an oncogenic process which alters the cistromes of active TFs.

It is apt that the activity of chromatin-associated proteins, their abundance and stoichiometry will have an effect on chromatin structure and its global degree of relaxation, thereby dictating the accessibility of TFs to bind the genome. The set of accessible elements in 


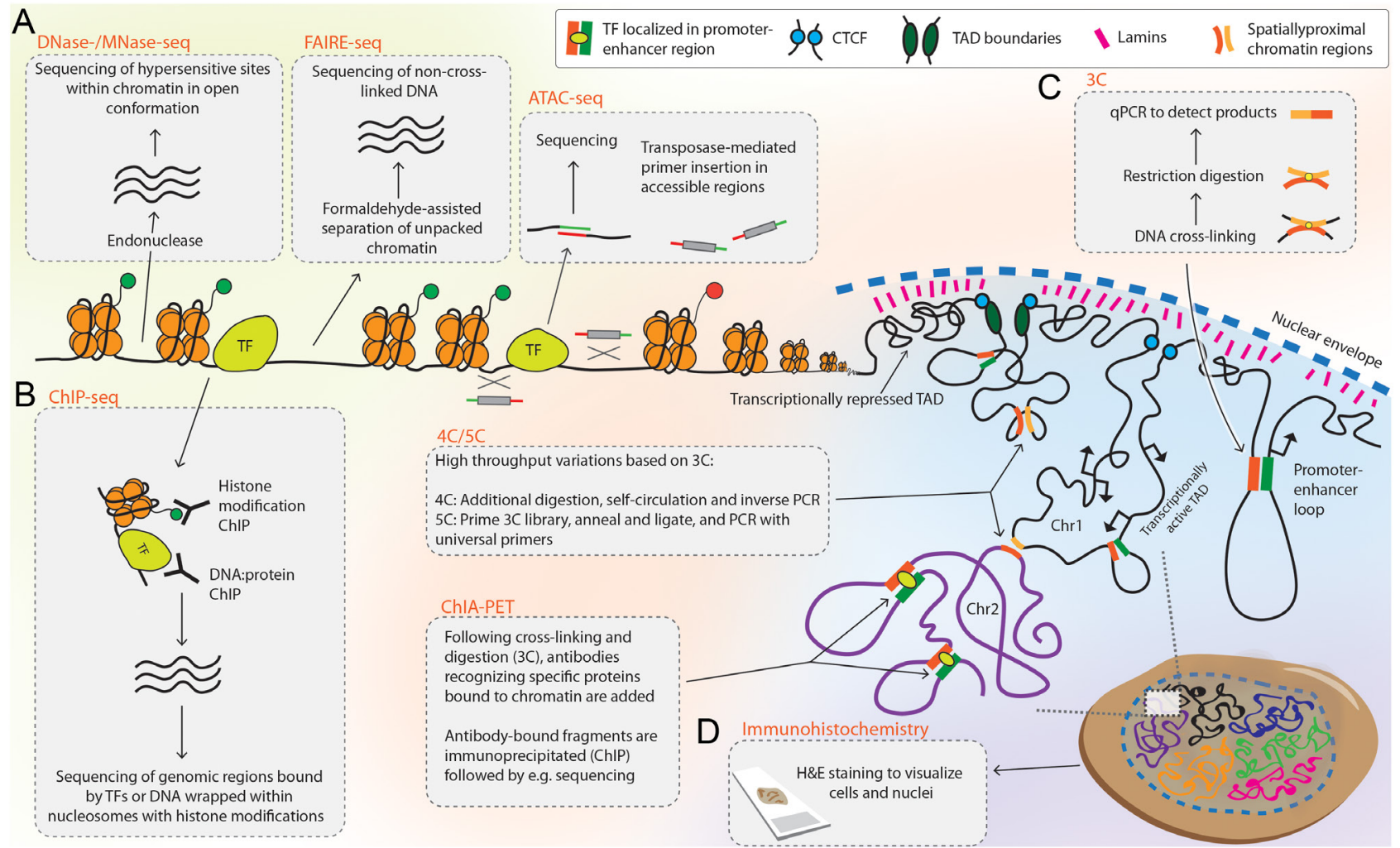

\section{Figure 1}

Methods for studying the chromatin structure and chromatin-associated proteins. (A) Non-immunoprecipitation-based methods for assessing chromatin in open conformation include DNase or MNase. These methods enrich for chromatin sites hypersensitive to enzymatic digestion and can be used to assess regulatory or nucleosome-free regions, respectively. Regulatory regions within chromatin in open conformation can also be assessed by FAIRE-seq, in which nucleosome-free DNA is isolated with a phenol-chloroform extraction and sequenced. In ATAC-seq, hyperactive transposases allow for insertion of primers into accessible chromatin regions, and the resulting products can be sequenced. (B) ChIP-based techniques allow for identification and quantification of regions of DNA bound by either protein (e.g. transcription factors (TFs)) or histone modifications by immunoprecipitation with specific antibodies followed by, for example, sequencing. (C) The spatial conformation of higher order chromatin can be studied by chromosomal conformation capture (3C)-based techniques. These methods can assess both intra- and inter-chromosomal interactions between regions of DNA that localize in proximity to one another. $3 \mathrm{C}$ is used predominantly for promoter-enhancer interactions and is coupled to qPCR to quantify the products of these interactions. $4 \mathrm{C}$ is used to measure the interactions between one specific locus and the rest of the genome simultaneously by coupling $3 \mathrm{C}$ to sequencing. $5 \mathrm{C}$ requires knowledge of the interacting chromosomal regions, but can map all interactions within a genomic region by ligation of universal primers. ChIA-PET utilizes immunoprecipitation of proteins of interest within conformation-captured chromatin regions, thus utilizing both conformation capture and ChIP technologies. ChIA-PET is therefore used to study specific-interacting genomic regions facilitated by binding of particular TFs. (D) Finally, at the macroscopic level, immunohistochemistry can be used on formalin-fixed paraffin-embedded tissue or cells to visualize nuclear size and chromatin structures by microscopy. Chr, chromosome; H\&E, hematoxylin and eosin; Seq, sequencing; TAD, topologically associating domain; TF, transcription factor.

the genome is associated with the cell transcriptional program and it is therefore defined at least in part by the chromatin structure. In this context, reprogramming of the chromatin structure is a remodeling of the chromatin that alters the patterns of open and closed chromatin, altering the set of accessible elements in the genome, suggesting that alterations to chromatin structure spanning genes' regulatory elements are likely to have an impact on the transcriptional output.

In this review, we highlight the importance of alterations in chromatin structure and remodeling processes that are able to confer PC plasticity and facilitate the emergence of drug resistance to AR-targeted therapies. Although multiple chromatin reader proteins and remodelers exist, we emphasize here the impact of bromodomain-containing proteins (BRDs), as BRD inhibitors are in clinical development for PC patients.

\section{Chromatin relaxation is a feature of prostate cancer}

The term 'chromatin relaxation' relates to the process in which the chromatin changes to a more open conformation 
and allows genes that otherwise are sterically restricted from being transcribed to become transcriptionally active. This process happens through chromatin remodeling that allows for binding of highly specific TFs to genes' regulatory elements (enhancers and/or promoters). Therefore, chromatin remodeler proteins and chromatinassociated proteins are key regulators of both gene transcription and chromatin structure. These proteins open or close the structure of the tightly packed chromatin by modulating the make-up of the histone tails with covalent modifications such as acetylation, methylation and ubiquitylation that are commonly defined histone posttranslational modifications (PTMs). Chromatin writers add PTMs, while erasers remove them. The consequential change in histone charge can induce nucleosome eviction, which leads to unwinding of negatively charged DNA. This in turn exposes regulatory elements on the DNA to binding of TFs, facilitating assembly of the transcriptional machinery. Thus, chromatin relaxation renders the chromatin transcriptionally permissive. Conversely, chromatin remodeling can repress transcription by wrapping the DNA more tightly around newly introduced nucleosomes and consequently tightening the chromatin structure, thereby preventing TFs binding (reviewed in Lee \& Young 2013). Most of the chromatin remodeling is mediated by chromatin readers, which recognize histone PTMs. A number of reader domains have been identified with affinity for different PTMs, such as methylation (e.g. PHD (plant homeodomain), chromo (chromatin organization modifier), Tudor, MBT (malignant brain tumor)) or acetylation (e.g. BRDs) (Yun et al. 2011).

An example suggesting that chromatin of cells in fast progressing PCs may be reprogrammed and in a more relaxed conformation than their benign counterparts comes from immunohistochemical studies of the trimethylation of histone 3 lysine 27 (H3K27me3). $\mathrm{H} 3 \mathrm{~K} 27 \mathrm{me} 3$ is a polycomb heterochromatin marker and is widely known to be associated with chromatin compaction and transcriptional repression of proximal genes. Analyses of $\mathrm{H} 3 \mathrm{~K} 27 \mathrm{me} 3$ protein levels by quantitative immunohistochemistry (IHC) in BPH, premalignant prostate intra-epithelial neoplasia, primary PC and CRPC have shown an inverse correlation with worsening disease, in which high-grade tumors show the lowest levels of H3K27me3 (Pellakuru et al. 2012, Xu et al. 2012). Interestingly, IHC quantification of the levels of H3K9me2, another mark associated with transcriptional repression, was also found to be associated with disease outcome, with lower levels predicting poorer prognosis in prostate and other cancers (Seligson et al. 2009).
Multiple mechanisms that alter the charge of histones and that are associated with increased chromatin opening and rate of transcription are well characterized. IHC analysis of global levels of mono-, di- and trimethylated H3K4 (H3K4me1/2/3), which are marks of active transcription, and acetylated H3K18 (H3K18ac), which marks TSS in actively transcribed genes or genes poised for transcription, have been shown to be independent predictors of recurrence in PC patients (Seligson et al. 2005, Ellinger et al. 2010, Zhou et al. 2010).

Global levels of $\mathrm{H} 3$ and $\mathrm{H} 4$ acetylation have also been investigated in nonmalignant prostate tissue and various stages of PC including clinically localized PCs and advanced CRPCs. Interestingly, CRPC tumors showed lower levels of histone acetylation than localized tumors in one study by Ellinger et al. (2010), but the number of normal tissues stained was low and only one tenth of the number of PCs. Seligson et al. highlight a global increase of histone acetylation with disease stage and percentage of proliferating cells, albeit with inter-individual variability in staining intensities (Seligson et al. 2005), which may also explain the results obtained by Ellinger $e t$ al.

Acetylation of many other lysines in the histone tails, such as H3K9ac or H3K27ac, is catalyzed by histone acetyltransferases (HATs), and these also are generally associated with chromatin relaxation and transcriptional activity (Dancy \& Cole 2015). These HATs, including p300/ CREB-binding protein (CBP), are often overexpressed in PC and associated with poor outcomes (Debes et al. 2003, Comuzzi et al. 2004, Dancy \& Cole 2015). A recent study also suggested that global increases in histone acetylation could be a mechanism of chemoresistance in PC (Xu et al. 2018).

Collectively, IHC studies of histone modifications suggest that global histone modification expression pattern goes hand in hand with tumor progression and therapy resistance. Moreover, the global increase of marks associated with active transcription and open chromatin, and concomitant loss of repressive marks such as H3K27me3, during disease progression falls in line with increasingly decondensed (relaxed/permissive) chromatin observed during cancer progression (Timp \& Feinberg 2013).

Chromatin condensation, leading to transcriptional repression, can be catalyzed by the ATP-dependent SWI/SNF, ISWI, Mi2/NuRD families of proteins. These proteins function by promoting nucleosome formation and DNA re-packing and are key regulators of cellular proliferation. Upon functional loss of SWI/SNF, transcription of proliferation-associated genes is turned 
on (Längst \& Manelyte 2015). Importantly, these proteins are often lost or mutated in CRPC (Medina \& SanchezCespedes 2008, Grasso et al. 2012), indicating that the loss of ATP-dependent nucleosome formation and subsequent chromatin decondensation may give a selective advantage conferring therapy resistance.

Recently, using ATAC-seq, the landscape of open chromatin was profiled in over 20 human tumor types (Corces et al. 2018, Taipale 2018). The study by Corces and colleagues revealed cancer type-specific enrichment of DNA-binding motifs for TFs that indeed are known to be active in the respective cancer types. This included, for instance, the microphthalmia-associated transcription factor (MITF), which is important in melanoma, and the AR in PC (Corces et al. 2018, Taipale 2018). These findings represent an indication that chromatin in open conformation is able to drive tumor growth by allowing binding of key TFs. Moreover, specifically, the capacity of $\mathrm{AR}$ in driving PC is tightly linked to the degree by which the $\mathrm{AR}$ is able to access the genome.

By employing ChIP-seq in clinical samples, Sharma and colleagues previously reported that $\mathrm{AR}$ binding to chromatin is enhanced in CRPC tissue compared to that of primary $\mathrm{PC}$ or benign prostate hyperplasia $(\mathrm{BPH})$ (Sharma et al. 2013). Comparing ARBSs in PC from RP specimens and normal adjacent tissue, Pomerantz et al. have also reported that the genome-wide set of ARBSs is extensively and consistently reprogrammed during prostate tumorigenesis (Pomerantz et al. 2015). As the AR requires permissive, open chromatin to bind to its target elements on the DNA, Stelloo et al. and we have investigated whether the chromatin structure of CRPC specimens is more relaxed than that of primary PC or BPH (Stelloo et al. 2015, Urbanucci et al. 2017). In both studies, FAIRE-seq was applied to clinical specimens of benign prostate tissue, and tumor specimens from primary untreated PC, locally recurrent PC and metastatic CRPC. CRPC specimens had the highest number of both genomic sites showing chromatin in open conformation and sequenced reads at these sites (Stelloo et al. 2015, Urbanucci et al. 2017), indicating that the number of cells displaying chromatin in open conformation was also increased with disease stage, as illustrated in Fig. 2.

An integrative analysis of chromatin structures, methylation and transcriptomes in patient samples, revealed that open chromatin proximal to gene transcriptional start sites (TSSs) was positively correlated with expression of those genes, while DNA methylation within 1 and $5 \mathrm{~kb}$ around the genes' TSSs were instead negatively correlated with gene expression

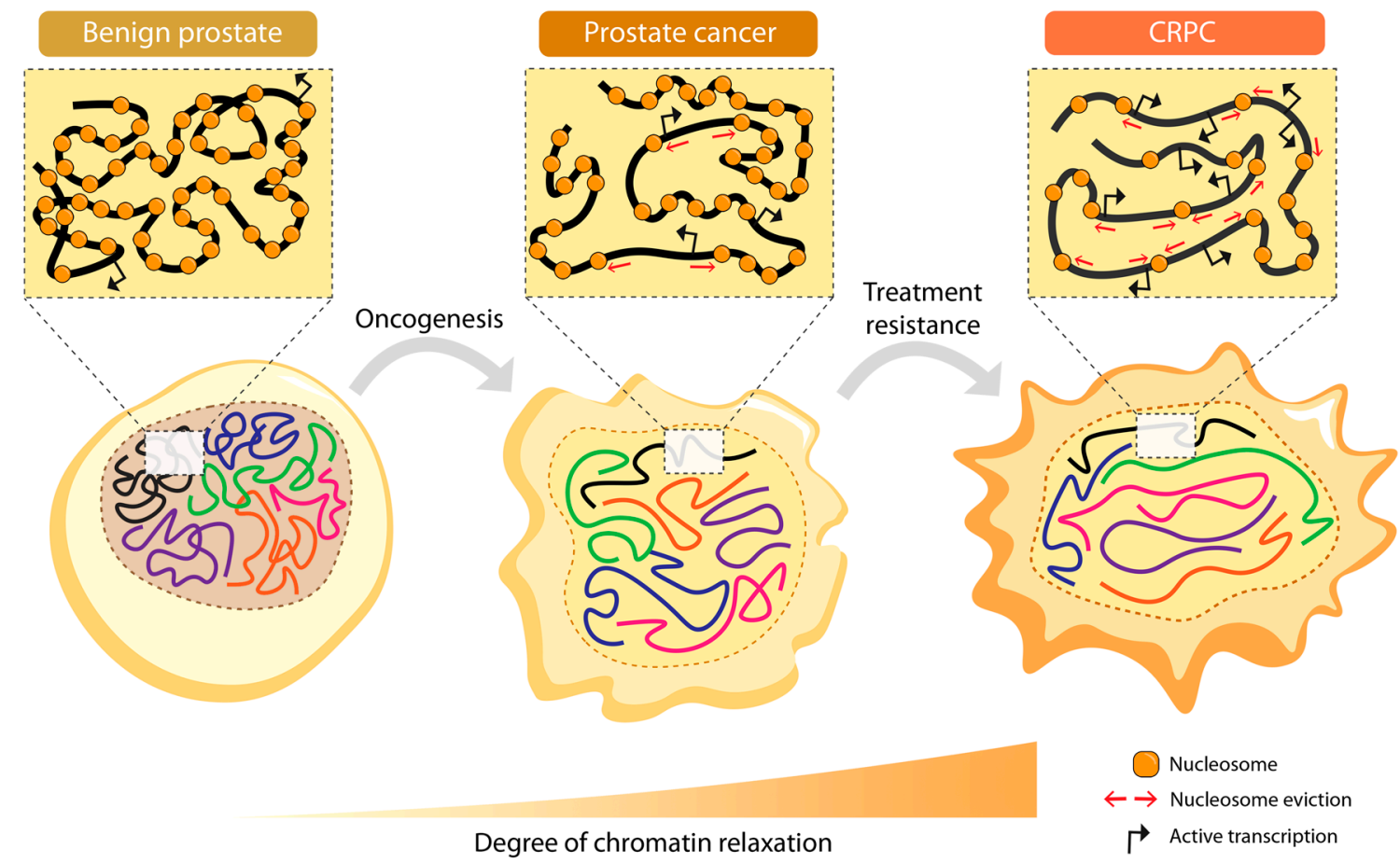

Figure 2

Chromatin relaxation during prostate cancer oncogenesis and progression. Schematic illustration of progressively open chromatin during following prostate cancer oncogenesis, subsequent acquisition of therapy resistance and CRPC development. 
(Urbanucci et al. 2017). This reinforces the notion that gene transcription is dictated by the chromatin structure and is in agreement with previous studies showing local DNA methylation to negatively correlate with transcript abundances (reviewed in Cedar \& Bergman 2012). By integrating chromatin structural information and transcriptomic data, gene expression patterns have been found to correlate with genes proximal to open chromatin and negatively correlate with TSS methylation in BPH, primary PCs and CRPC specimens (Urbanucci et al. 2017). The consistency of these correlations across different disease stages is supportive of other studies showing occurrence of epigenetic deregulation both during tumor initiation and progression to therapy resistance (Perry et al. 2010, Ruggero et al. 2018).

Interestingly, patterns of chromatin in open conformation were on average similar in $\mathrm{BPH}$ and primary tumor specimens while they appeared different in CRPC specimens (Urbanucci et al. 2017). This suggests that extensive chromatin reprogramming occurs during emergence of therapy resistance and pinpoints a more marked role of chromatin remodeling in the emergence of CRPC rather than in PC development. By inter-patient sample analyses, we observed that the core set of genomic regions in open conformation were very similar in both benign tissue and primary PC tumors. In CRPC samples, on the other hand, we observed a large variation in interpatient samples (Urbanucci et al. 2017). Collectively, it seems plausible that selective and/or adaptive remodeling events occur mainly upon treatment challenge and that these events are predominantly stochastic.

Chromatin remodeling events can alter cells' transcriptional state, leading to a higher probability of permitting transcription of key genes involved in cancer growth and drug resistance (Sur \& Taipale 2016). Pomerantz et al. exemplified this phenomenon in PC tumorigenesis where they identified FOXA1 and HOXB13 colocalizing within the reprogrammed AR cistrome (Pomerantz et al. 2015). Forced expression of FOXA1 and HOXB13 into an immortalized prostate epithelial cell line reprogrammed the AR cistrome to resemble that of a clinical prostate tumor (Pomerantz et al. 2015), which functionally links these specific TFs to ARBSs reprogramming. Therefore, chromatin remodeling triggered by pioneer factors such as FOXA1 or HOXB13 that allow increased and reprogrammed binding of TFs such as the AR, and the increased accessibility of the DNA given by a more relaxed chromatin in advanced PC, may help to explain the increased rate of transcription observed in CRPC compared to primary tumors (Taylor et al. 2010, Sharma et al. 2013, Ylipaa et al. 2015,
Robinson et al. 2015, Latonen et al. 2018); a phenomenon that has been attributed historically to the increased levels of AR in these tumors. By high-throughput mass spectrometry proteomic profiling, Latonen et al. showed that the discrepancies in protein profiles vs the matched transcriptional output disease stage-wise were greater in CRPC than in primary PC. From this it can be inferred that the increased transcriptional dosage observed in CRPC does not translate directly into corresponding proteins. Latonen et al. also identified a group of miRNA-protein pairs that were found to be negatively correlated (Latonen et al. 2018). This implies that buffer regulatory mechanisms should be actively 'getting rid' of transcriptional (e.g. by miRNAs) and translational (e.g. the unfolded protein response and autophagy) byproducts of the escalating overproductive transcriptional machinery.

Finally, multiple genomic alterations occur upon therapeutic challenge as a means for the tumor cells to adapt to the exerted pressure and to alleviate their addiction towards the drug-targeted pathways. The notion that an open chromatin structure may increasingly permit these alterations, such as structural variations, including gene rearrangements, copy number alterations and genomic breakpoints, has prompted studies associating these events with chromatin structure in PC. DNA breakpoints were recently found to be associated with open and transcriptionally active chromatin in PC (Gerhauser et al. 2018). Through deep sequencing-based genomic analyses of early- and late-onset primary PCs, it was earlier shown that whereas structural rearrangements were stochastic in late onset PC (i.e. increasingly likely with increasing age), the rearrangements were associated with ARBSs in early-onset PC (Weischenfeldt et al. 2013). More recently, a breakpoints analysis revealed an increased rate of DNA double-strand breaks in functionally active chromatin regions (Gerhauser et al. 2018). As androgen signaling has been shown to induce DNA damage which can facilitate genetic rearrangements, for example, between the TMPRSS2 and the ERG genes (Mani et al. 2009, Haffner et al. 2010), it is therefore conceivable that increased chromatin accessibility creates more opportunities for random structural rearrangements likely to contribute to PC development and progression to CRPC. Accordingly, a recent study by Quigley et al. discovered tandem duplications associated with notoriously open chromatin structures at multiple enhancers near $A R, M Y C$ and FOXA1 by deep whole-genome analysis of 101 CRPC metastases. Intriguingly, $80 \%$ of the cases showed local amplification of the enhancer proximal to $A R$, which correlated with increased $A R$ transcription (Quigley et al. 2018). 
Taken together, these studies show that chromatin relaxation is a feature of PC and that chromatin opening is associated with increased gene transcription and reprogramming of the global transcriptional output through aberrant TFs binding and increased rate of DNA structural variants.

\section{The androgen receptor drives chromatin relaxation as an oncogenic feed-forward process}

AR signaling modulates gene transcription during embryonic development and maturation of the healthy prostate and is overexpressed in PC leading to transcriptional reprogramming, which promotes disease progression (Matsumoto et al. 2013). More than a decade ago, the group of Charles Sawyers demonstrated that AR overexpression alone is able to drive PC cells to castration resistance (Chen et al. 2004).

Interestingly, consequences of activation or reactivation of TFs have been extensively studied with the Yamanaka factors (OCT4, SOX2, KLF4 and c-MYC) in the induction of pluripotent stem cells from adult human fibroblasts, and it is apt that this process is associated with considerable epigenetic reprogramming (Takahashi et al. 2007, Schmidt \& Plath 2012). The role of these TFs in PC have been reviewed in Ruggero et al. (2018). In PC, reprogramming of normal human epithelial prostate tissue to a lethal neuroendocrine cancer lineage has proven successful by forcing the expression of TFs such as c-MYC or N-MYC in combination with myristoylated AKT1 (a partial mimic of PTEN loss) (Park et al. 2018). This experiment proves that overexpression of TFs in cancer is a common mechanism of cell plasticity which may lead to drug resistance and tumor progression.

Several studies now suggest that also the AR is implicated in shaping the chromatin structure by modifying the activity of epigenetic factors (Takayama 2018). Through transcriptomic profiling of isogenic AR-overexpressing CRPC cell line models ('mimicking' adenocarcinoma-CRPC) and LuCaP PDXs with different AR expression levels (Urbanucci et al. 2008, 2012a,b, 2013 Waltering et al. 2009, 2011, Jalava et al. 2012), it was shown that high AR levels associated with increased expression of androgen-responsive genes and AR coregulators.

Many AR coregulators have been described and many AR coactivators are overexpressed in primary PC and CRPC (Linja et al. 2004, Heemers \& Tindall 2007, Liu et al. 2017). Interestingly, we showed that a number of the AR coregulators were AR regulated and that enhanced expression of a subset of these coregulators was observed in castration-challenged PC cells ectopically overexpressing AR (Urbanucci et al. 2008). Among the androgen-regulated coregulators identified were amplified in breast cancer 1 (AIB1) and CBP, both HATs which have been shown to increase nuclear receptors' activities and are implicated in mechanisms of drug resistance (Chang \& Wu 2012, Culig 2016, Jin et al. 2017).

Other coregulators of $\mathrm{AR}$, such as lysine-specific histone demethylase 1A (LSD1), have been shown to have a reprogrammed activity in CRPCs, where it is also highly expressed (Liang et al. 2017, Sehrawat et al. 2018). Importantly, LSD1 has been shown to be one of the responsible factors for $A R$ in castration-challenged PC cells (Cai et al. 2011).

Of note, several of the AR-upregulated AR coactivators, including the mentioned $\mathrm{CBP} / \mathrm{p} 300$ and SRC1, have been shown to exert chromatin remodeling functions, for example through histone modifications (Bannister \& Kouzarides 2011), thus hinting that AR overexpression may increase the likelihood of further oncogenic events by upregulating chromatin-associated proteins.

In two independent preclinical AR-overexpression model systems, one of which was isogenic and therefore more independent of confounding factors (Waltering et al. 2009), we demonstrated that androgen treatment in AR-overexpressing cells led to enhanced AR recruitment with faster kinetics (Urbanucci et al. 2012a,b). Increased H3K9 acetylation in nucleosomes flanking ARBSs was found in the isogenic AR-overexpressing cell line models in key genes regulatory regions such as enhancers and promoters (Urbanucci et al. 2012a). Interestingly, these ARBSs appeared deprived of nucleosomes (Urbanucci et al. 2012a). This indicated that AR overexpression might seed further AR recruitment at ARBSs through increasing chromatin permissiveness. Corroborative of this, we have shown by ChIP-seq that high AR expression was associated with an increased number of ARBSs and intensity of AR binding to the chromatin (Urbanucci et al. 2012b).

These observations were later confirmed using FAIRE-seq, as AR overexpression drove genome-wide chromatin relaxation in two independent cell line models, concomitant with increased permissiveness to ARBSs (Urbanucci et al. 2017). We found that high levels of AR were associated with increased number of chromatin sites in open conformation and higher number of sequenced reads at these sites (Urbanucci et al. 2017), indicating that the number of cells displaying chromatin in open conformation was also increased in AR-overexpressing 
cells. The addition of androgens affected primarily increased opening at ARBSs (Urbanucci et al. 2017) suggesting an AR-mediated feed forward loop increasing chromatin opening at these sites. This study supports the notion that ligand-mediated, AR-driven chromatin remodeling in the context of the AR overexpression may confer transcriptional permissiveness at ARBSs (Urbanucci et al. 2017). This would represent a positive feedback loop in which the AR promotes chromatin remodeling which in turn permits the AR to more tightly bind to ARBScontaining chromatin regions.

Historically, the first studies on how AR drives target gene transcription utilized ChIP-qPCR to investigate the loading of AR, RNA Pol II and AR coactivators onto the prostate-specific antigen (PSA/KLK3) regulatory regions (Kang et al. 2002, Kang et al. 2004). Later on, multiple studies have used ChIP-chip and ChIP-seq to map AR binding onto chromatin in cell line models and tissue samples (Wang et al. 2009, Yu et al. 2010, Massie et al. 2011, Sahu et al. 2011, Urbanucci et al. 2012b, Sharma et al. 2013, Pomerantz et al. 2015), revealing that AR activity is hijacked or reprogrammed in PC to respond to oncogenic insults and activate oncogenic transcriptional programs (reviewed in Mills 2014).

The molecular events leading to the aberrant pattern of AR-binding onto chromatin in therapy-challenged PC tumors can be attributed to several interconnected factors, possibly depending on the administered intervention strategy: (i) overexpression of the AR protein that increases the abundance of the nuclear AR and the probability that the AR binds the chromatin (Jia et al. 2006, Wang et al. 2009, Yu et al. 2010, Massie et al. 2011, Urbanucci et al. 2012a,b, Sharma et al. 2013, Stelloo et al. 2015); (ii) alterations of the activity of proteins that enable binding of AR to the chromatin (pioneer factors) by triggering the recruitment of chromatin remodelers (Jia et al. 2008, Lupien et al. 2008, Sahu et al. 2011, Robinson et al. 2014, Pomerantz et al. 2015, Zhao et al. 2016); (iii) alterations in the composition of the proteins within the AR transcriptional complex which also include a number of co-regulatory proteins (Kotaja et al. 2002, Kang et al. 2004, Heemers \& Tindall 2007, Jia et al. 2008, Jariwala et al. 2009, Rytinki et al. 2011, Chen et al. 2013, Liu et al. 2017, Stelloo et al. 2018) and (iv) alterations in the chromatin structure and composition, which renders it more permissive toward AR binding (Jia et al. 2006, He et al. 2010, Yu et al. 2010, Andreu-Vieyra et al. 2011, He et al. 2012, Tewari et al. 2012, Stelloo et al. 2015, Urbanucci et al. 2017).
The AR preferentially binds to nucleosome-deprived regions with access to regulatory elements (Jia et al. 2008), suggesting that preceding chromatin remodeling and, for example, pioneer factor binding may be necessary to permit AR binding to otherwise transcriptionally restricted AREs: In ARBS-containing regulatory regions (primarily enhancers) proximal to specific AR target genes, the chromatin is open even in absence of AR binding (Andreu-Vieyra et al. 2011, He et al. 2018). The reason for the pre-determination of these sites is still partly unclear, although many factors have been identified to cooperate in order to maintain a permissive chromatin structure to enable AR binding, such as GATA2 and FOXA1 (Fig. 3) (He et al. 2010, Andreu-Vieyra et al. 2011). GATA2 is an important mediator of androgen signaling within the hierarchical binding of other transcriptional regulators responsible for AR activity (Wang et al. 2007, Jia et al. 2008, Rodriguez-Bravo et al. 2017) and has been shown to act downstream of FOXA1 in modulating AR binding to chromatin (Zhao et al. 2016). FOXA1 has been further characterized as a pioneer factor for characterizing the AR and estrogen receptor (ER) cistromes in both prostate and breast cancer (Lupien et al. 2008, Robinson et al. 2011, Sahu et al. 2011, Wang et al. 2011, Zhang et al. 2011). More studies are needed to understand how FOXA1 is regulated. However, recently, a study by Wang and colleagues showed that in breast cancer cells, the activity of FOXA1 can be modulated by multiple kinases and that the cell cycle control kinase CDK1 may directly phosphorylate FOXA1 (Wang et al. 2018b).

Tewari and colleagues showed using DNase-seq that the AR not only binds to pre-docked open chromatin, but is able to induce chromatin remodeling events by itself, which alters the accessibility of chromatin (Tewari et al. 2012). The identified regions of increased chromatin accessibility were enriched with ARBSs, and these regions were associated with increased $\mathrm{H} 3$ acetylation and enhanced transcription of AR-regulated genes (Tewari et al. 2012). He and colleagues proposed a model in which AR binding to chromatin favors the eviction of local nucleosomes (He et al. 2012). This was later confirmed by Taberlay et al. (2014). Although it remains elusive how this putative nucleosome eviction takes place, AR-interacting proteins with chromatin remodeling functions in the transcriptional subcomplexes are likely to play a role (Stelloo et al. 2018).

Supportive of an indirect role of AR bindingmediated chromatin remodeling, remodeling proteins FOXA1 and HOXB13 are known to co-localize with
(C) 2019 Society for Endocrinology Published by Bioscientifica Ltd. Printed in Great Britain 

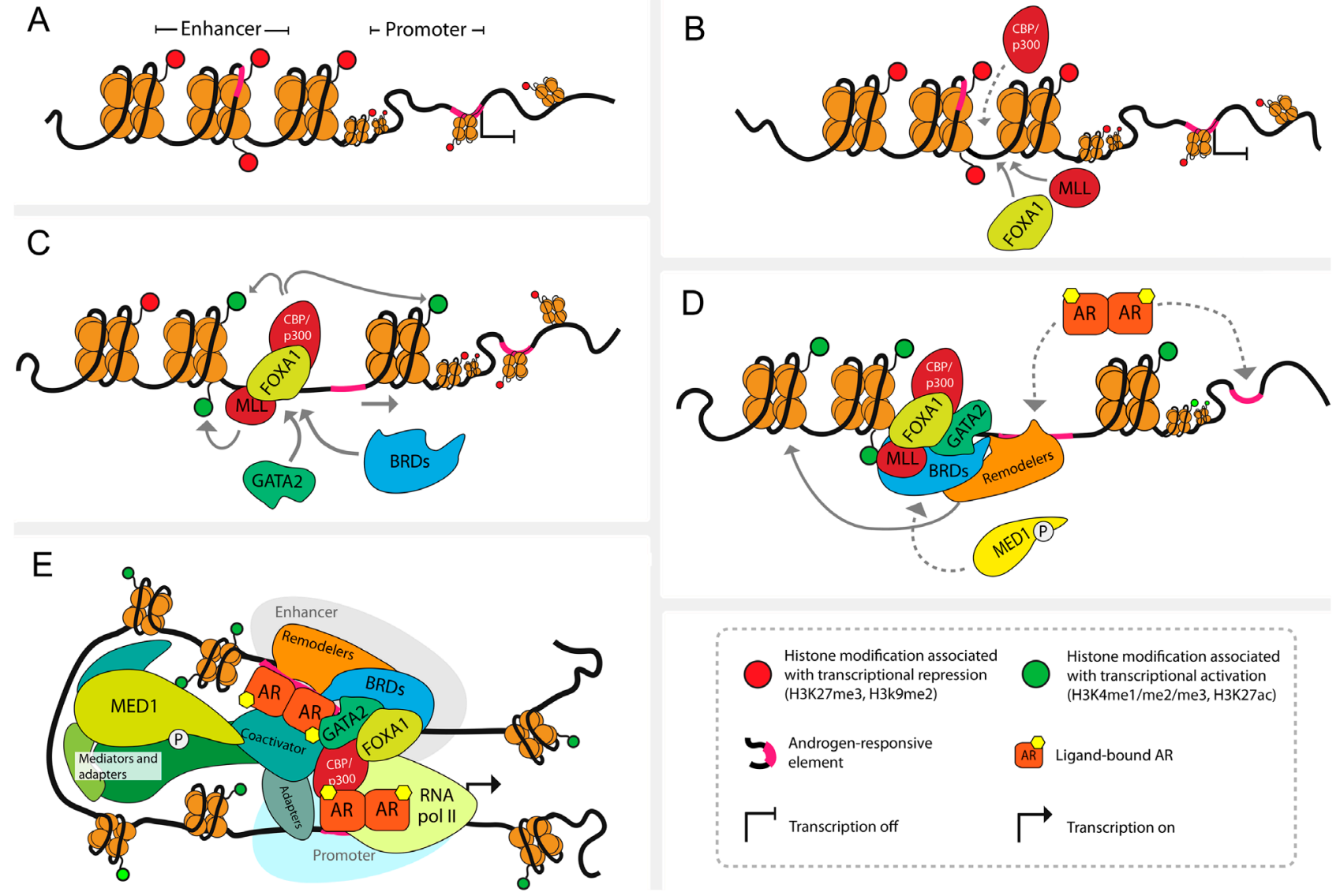

\section{Figure 3}

Mechanism of chromatin remodeling associated with androgen receptor binding to chromatin. (A) Androgen-responsive elements (AREs) residing in genomic regions with transcriptionally repressive histone marks may not directly permit AR binding. The pioneering TF FOXA1 may bind directly to condensed chromatin near regulatory enhancer elements and facilitate recruitment of coregulators such as CBP/p300 and MLL (B), which regulate chromatin opening through their histone acetylase and methyltransferase activities, respectively (C). GATA2 may also act as a pioneering factor and increased acetylation is captured by bromodomain-containing proteins, e.g. BRD4 or ATAD2, which further boost local chromatin opening and exposes sequences recognizable by TFs such as activated AR. (D and E) PI3K/AKT-phosphorylated MED1 may recognize FOXA1 and promote chromatin looping which increases enhancer-promoter interactions and RNA polymerase-mediated transcription. Additional chromatin remodelers may be recruited in the cascade, collectively permitting ligand-activated, dimerized AR binding to AREs. BRDs, bromodomain-containing proteins.

AR subcomplex on the chromatin (Stelloo et al. 2018). FOXA1 has been shown to recruit chromatin-remodeling complexes such as the MLL complex to deposit H3K4 mono- and dimethylation marks at histones flanking gene regulatory regions (Jozwik et al. 2016). However, the sole activity of FOXA1 cannot explain how the AR is able to open chromatin, as, paradoxically, knocking down FOXA1 in PC and breast cancer cells increases the number of ARBS (Robinson et al. 2011, Sahu et al. 2011, Wang et al. 2011). Moreover, overexpressing FOXA1 in PC cells leads to novel ARBSs, but at locations different from the de novo AR-binding sites identified upon FOXA1 knockdown (Robinson et al. 2014). In stark contrast to the reprogramming functions of FOXA1 on the AR cistrome, FOXA1 is required for ER to bind chromatin, and FOXA1 loss abrogated the capacity of the ER to bind chromatin in breast cancer cells (Hurtado et al. 2011). This implies that FOXA1's pioneering activity on different TFs is mediated by other factors. HOXB13 might be one such pioneer TF (Pomerantz et al. 2015), but its role in reprogramming the AR cistrome in PC, and possibly in breast cancer, has not been clearly characterized. In PC, AR target genes important for driving emergence of castration resistance, such as ubiquitin-conjugating enzyme E2 C (UBE2C), have been shown to be overexpressed upon FOXA1 recruitment through PI3K/AKT phosphorylated MED1, collectively favoring looping between its promoter and distant regulatory regions (Chen et al. 2011). This indicates that there are a number of factors that pioneer and mediate AR transcriptional output.

Levels of AR variants lacking the LBD were shown to be increased in specimens from CRPC patients 
(Watson et al. 2010, Antonarakis et al. 2014, Sharp et al. 2019) and to contribute to resistance to enzalutamide and abiraterone (Sharp et al. 2019). Interestingly, evidence of a distinct ligand-independent chromatin-binding profile of constitutively active AR splice variants (Lu et al. 2015, Chen et al. 2018) could be the result of the chromatin being incidentally more relaxed in CRPC. Moreover, recently, Chen and colleagues showed that HOXB13 directly interacted and pioneered binding of one of the most abundant AR splice variants, AR-V7, thereby suggesting cooperation in upregulating target oncogenes (Chen et al. 2018).

Given the increased chromatin relaxation observed in CRPCs compared to primary PCs, it is apt that mechanisms leading to enhanced transcription are possibly dependent on the increased chromatin opening at newly activated enhancers. Accordingly, the group of Susan Clark showed that a variant of Histone H2A (H2A), namely H2A.Z, is involved in exposure of packed and 'unbound' enhancers; a process that leads to AR binding to these 'neo-enhancers' (Valdes-Mora et al. 2017). H2A.Z is predominantly found at promoters, however, and has been shown to be important in maintenance of poised bivalent promoters in stem cells (Rudnizky et al. 2016, Surface et al. 2016). In particular, mono-ubiquitylated H2A.Z competes with BRD2, which promotes nucleosome eviction and chromatin opening, thus illustrating an antagonistic relationship between the two (Surface et al. 2016). Valdez-Mora et al. showed that acetylated H2A.Z is absent in nucleosomes of closed/ inactive chromatin at both distal enhancers and proximal promoters to ensure appropriate oncogenic silencing in normal cells (Valdes-Mora et al. 2017). However, in PC cells, H2A.Z-nucleosomes were present at new regulatory elements, promoting a poised local chromatin conformation. H2A.Z acetylation was associated with the formation of nucleosome-deprived regions and loss of DNA methylation at both enhancers and promoters, priming these new sites for gene transcription upon androgen stimulation. Supporting the relevance and oncogenic properties of H2A.Z, IHC staining of acetylated H2A.Z has been shown to be increased in PC and was associated with poor prognosis (Valdes-Mora et al. 2017). This body of work shows that PC initiation and progression is associated with increased local chromatin opening, which leads to increased AR binding, and is in line with AR overexpression driving increased chromatin opening in advanced PC.

Collectively, present evidence shows that AR overexpression associates with increased expression of AR target genes and AR coregulators, many of which favor chromatin remodeling and are upregulated in CRPC. This transcriptional deregulation, in turn, favors chromatin relaxation through nucleosome eviction and is likely to drive PC progression by promoting stemness properties and plasticity in a oncogenic feed-forward process.

\section{Chromatin relaxation drives PC progression by altering the patterns of transcription factor binding to the chromatin}

Although substantial progress is being made to understand the mechanisms and players involved in chromatin reprogramming in $\mathrm{PC}$, the underlying mechanisms driving higher chromatin disorganization in cancers, including PC, are largely unknown. It is established that the chromosomal conformation inside the nuclear envelope favors engagement of highly interactive chromatin substructures of approximately $1 \mathrm{Mb}$ called topologically associated domains (TADs) (Yaffe \& Tanay 2011). Reconfigured and altered TADs have been shown in PC cells to be enriched with regulatory elements such as enhancers, promoters and insulators, and were associated with alterations in gene expression (Taberlay et al. 2016). Boundaries of TADs have been shown to be dependent on transcriptional repressor CTCF, in the sense that CTCF is able to mark chromatin regions within active and inactive TADs, and loss of CTCF can highly deregulate not only the chromatin conformation but also transcription of genes within these TADs (Ghirlando \& Felsenfeld 2016).

Several groups have shown that newly generated TAD boundaries delineated by CTCF are acquired during prostate carcinogenesis (Taslim et al. 2012, Taberlay et al. 2016). Fiorito et al. have previously shown in breast cancer cells that the presence of CTCF at enhancer regions resulted in modulation of estrogen-induced gene transcription by preventing ER-chromatin binding and by hindering the formation of additional enhancerpromoter looping (Fiorito et al. 2016). Depletion of CTCF facilitated the expression of ER target genes associated with cell division and increases the rate of breast cancer cell proliferation. Fiorito et al. have also shown that CTCF mediated contact of the regulatory regions to the nuclear lamina (Fiorito et al. 2016). This process was regulated by estrogens, which altered the chromatin structure interfering with enhancer-promoters loop formation (Fiorito et al. 2016). Like in breast cancer, a role of CTCF in mediating hormone-dependent gene transcription has been shown in PC: Taslim and colleagues found that subsets of androgen-responsive genes were significantly 
enriched within the same CTCF blocks, suggesting that CTCF is implicated in regulation of a subset of distally located androgen-responsive genes (Taslim et al. 2012), which are potentially involved in prostate carcinogenesis (Taslim et al. 2012, Guo et al. 2018). Collectively, these studies show that the higher-order chromatin conformation is interconnected with local chromatin relaxation and interferes with gene regulation, which may have implications for PC development and progression.

Interestingly, performing extensive motif enrichment analysis of open chromatin regions in PC cell lines and clinical specimens of BPH, primary PCs and CRPCs, we found that CTCF-like motifs were the top-enriched motifs in both clinical specimens and cell lines, followed by ETSlike motifs (Urbanucci et al. 2017). Of note, both CTCFand ETS-like motifs were equally enriched in BPH as well as in primary PCs and CRPCs, supporting the notion that these TFs could be implicated in early tumorigenesis rather than progression and CRPC development. ETS rearrangements have been in fact characterized as an early event in PC (Weischenfeldt et al. 2013), while the role of CTCF in PC oncogenesis remains elusive. As opposed to CTCF-like and ETS-like motifs, c-MYC DNA-binding motifs were exclusively enriched in open chromatin regions found in CRPC samples (Urbanucci et al. 2017), which is in agreement with several studies suggesting that, although c-MYC activity may be responsible for tumorigenesis, MYC oncogenic activation is a late event in PC progression and is involved in CRPC emergence (Nupponen et al. 1998, Gurel et al. 2008, Ahmadiyeh et al . 2010, Hawksworth et al. 2010, Koh et al. 2010). Other TF motifs were also enriched in open chromatin regions of CRPC specimens, including glucocorticoid receptor (GR) motifs (Urbanucci et al. 2017), which is in agreement with recent data showing its reactivation in CRPC (Arora et al. 2013, Isikbay et al. 2014, Kroon et al. 2016, Culig 2017, Puhr et al. 2018).

Although the chromatin binding of these TFs has not been profiled in clinical samples, their expression profiles and transcriptional activities have been found to differ between CRPC subtypes with variable dependency on AR signaling. In the following section, we detail evidence collected in cell models that associate them with PC development, progression and emergence of AR-negative CRPC subtypes (Fig. 4).

\section{c-MYC}

c-MYC is overexpressed in a subset of PCs and c-MYC overexpression in primary $\mathrm{PC}$ is associated with biochemical recurrence following RP (Hawksworth et al. 2010). Mechanistically, the overexpression of TFs such as AR and c-MYC results from pressure put upon PC cells to survive and sustain growth in androgen-deprived environments, as is the case in patients undergoing ADT or androgen blockade (Waltering et al. 2009, Ni et al. 2013). Importantly, overexpression of c-MYC has been shown to confer androgen-independent growth in PC cells (Bernard et al. 2003). We confirmed these findings using an isogenic LNCaP cell-based model with enforced inducible MYC overexpression (Barfeld et al. 2017). Using ChIP-exo sequencing, a variant of the ChIP-seq protocol that utilizes exonucleases for improved resolution of TF binding sites (Rhee \& Pugh 2012), we further investigated the interplay of c-MYC with AR on chromatin and the transcriptional output in the context of c-MYC overexpression (Barfeld et al. 2017). Overexpression of c-MYC partially reprogrammed AR chromatin occupancy, although the binding of c-MYC itself was not substantially altered. Interestingly, c-MYC overexpression was accompanied by altered distribution of histone marks, most notably H3K4me1 and H3K27me3. This is consistent with previous findings showing that c-MYC expression is inversely correlated with global protein expression of H3K27me3 in PC (Pellakuru et al. 2012). More recently, Kieffer-Kwon and colleagues showed that c-MYC activation was essential for chromatin opening and decompaction during B cell activation (Kieffer-Kwon et al. 2017), which is in agreement with the above-mentioned studies. We also found that c-MYC overexpression triggered DNA damage in LNCaP cells independently of AR signaling being activated or not (Barfeld et al. 2017). DNA damage leads to dislocation of nucleosomes from the point of DNA damage, and chromatin remodeling is an integral part of the DNA damage response process (Audia \& Campbell 2016). Cellular levels of histones drop $20-40 \%$ in response to DNA damage, which is accompanied by chromatin decompaction and increased DNA fiber flexibility (Hauer et al. 2017). This suggests that, similar to AR overexpression, c-MYC overexpression in CRPC may be able to mediate chromatin reprogramming.

By performing interactome profiling (RIME: rapid immunoprecipitation mass spectrometry of endogenous proteins) for both AR and c-MYC, we found that a great part of TFs or coregulators interacting with both MYC and AR were indeed implicated in DNA damage response (Barfeld et al. 2017), thus supporting the role of both $\mathrm{AR}$ and MYC in controlling DNA damage response. We also found that c-MYC and the AR co-occupied a substantial number of binding sites in PC cells and these 

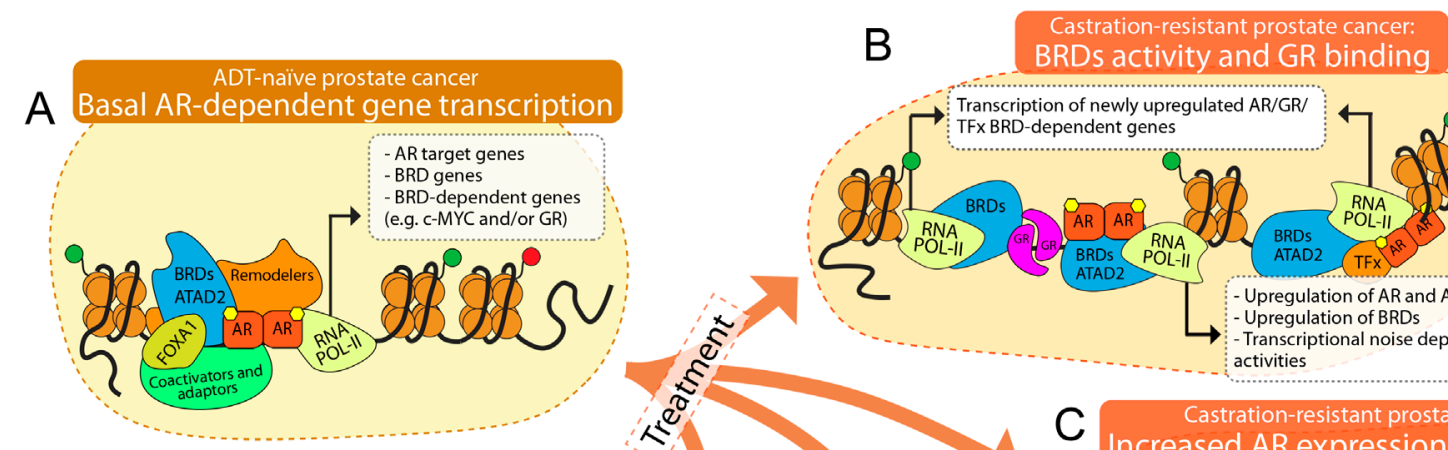

A Basal AR-dependent gene transcription

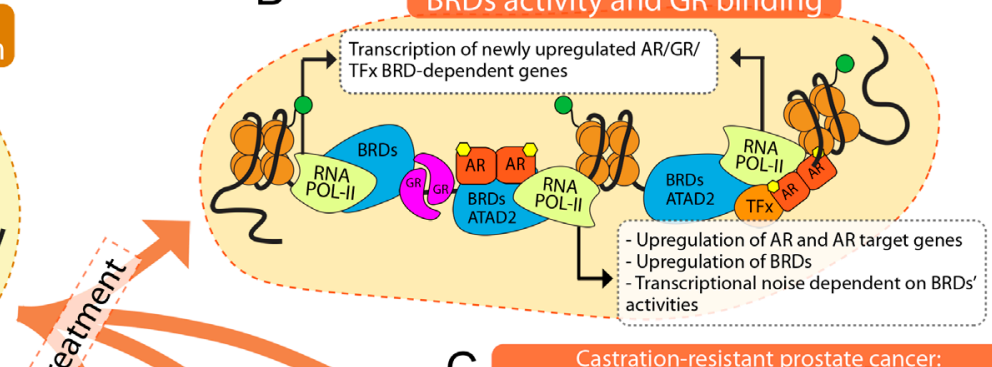

C Increased AR expression and binding
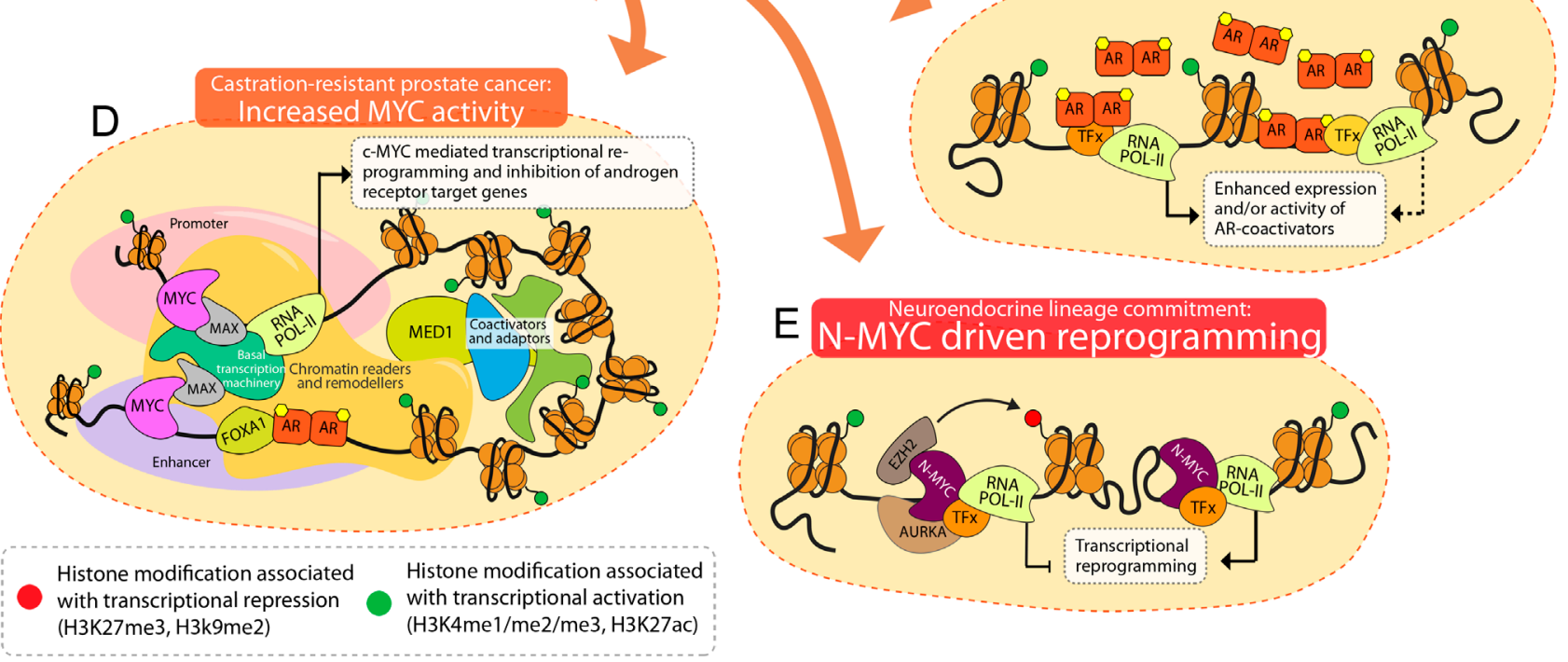

Figure 4

Proposed model for acquisition of plasticity and therapy resistance involving chromatin reprogramming in prostate cancer. (A) In androgen deprivation therapy (ADT)-naïve, primary PC, the androgen receptor (AR)-target genes, including KLK3 (PSA) and other bromodomain-containing proteins (BRDs)dependent genes are transcribed to maintain growth and survival of the tumor. In this context, gene transcription is mediated mainly by AR binding to defined regions of permissive chromatin, which facilitates recruitment of proteins required for transcriptional initiation. Upon treatment with AR-targeted therapies, events involving chromatin relaxation which facilitates emergence of castration-resistant prostate cancers (CRPCS) occur. (B and C) Events including AR overexpression are found in the majority of CRPCs, and can lead to enhanced expression and/or activity of AR coactivators, further promoting AR signaling and increasing BRD activity. In turn, this enhances the degree of chromatin relaxation, and promiscuous binding of activated or re-activated TFs such as, for example, glucocorticoid receptor (GR). (D) The scenario in which c-MYC overexpression leads to frequent c-MYC-binding events which promotes transcriptional reprogramming in concert with AR. (E) Continued suppression of AR signaling may confer lineage plasticity and therapy evasion through, for example, reactivation of N-MYC and N-MYC-mediated cell reprogramming. N-MYC-related reprogramming may involve epigenetic silencing through recruitment of the polycomb protein EZH2 or enhanced transcription of genes involved in promoting stem cell and/or basal-cell like features, which can alleviate AR dependence and thereby drive progression to treatment-related neuroendocrine CRPCs (t-NEPC) and other AR-low/null subtypes of CRPCs.

exhibited enhancer-like characteristics. We performed motif enrichment analysis of the AR and c-MYC ChIP-seq datasets and retrieved FOXA1 as one of the top enriched motifs in both. Therefore, it is possible that FOXA1 may pioneer opening at these sites in conditions in which, for example, c-MYC is overexpressed. Under these circumstances, c-MYC could have an increased chance to bind to chromatin sites pre-docked for AR by FOXA1. However, immunoprecipitation between c-MYC and AR from independent RIME experiments did not show direct interaction, nor did FOXA1 interacting with c-MYC (Barfeld et al. 2017). Previous studies in breast cancer cells have shown that MYC regulates androgen signaling via a context-specific activation of $A R$ in which c-MYC is able to co-opt the functions of other TFs to coordinate differential gene expression programs in a cell-type-dependent manner (Ni et al. 2013). However, in the same study, a direct interaction between c-MYC and AR was not demonstrated (Ni et al. 2013). Furthermore, unlike in apocrine breast cancer in which c-MYC is thought to be an amplifier of AR-driven gene transcription (Ni et al. 2013), we found in our study in PC that the AR-c-MYC interplay was largely antagonistic (Barfeld et al. 2017). (c) 2019 Society for Endocrinology Published by Bioscientifica Ltd. Printed in Great Britain 
Taken together, these studies of the interplay between c-MYC and AR activity suggest that different therapeutic approaches may impose different selective utilization of survival and drug resistance pathways depending on the hormonal environment and chromatin structure of the tissue.

\section{Steroid receptors and other transcription factors}

Binding of steroid receptors, such as AR, ER, GR and progesterone receptor (PR) to chromatin, are dynamic processes in which binding has been shown to occur in cycles of 'touch and go' to the regulatory regions of target genes (Carlberg \& Seuter 2010). Proteasomal activity towards the AR has also been proposed to play a role in the context of AR binding to chromatin (Kang et al. 2002, 2004). We showed that AR overexpression altered the dynamics of the AR binding to chromatin (Urbanucci et al. 2012a,b). More recently, the group of Gordon Hager has shown using microscopic techniques how the binding of steroid receptors can be divided into long- and short-lived events that lead to transcription of target genes. A great part of the unliganded/unstimulated steroid receptors may diffuse into the nucleus of the cells, from which a proportion of them can in fact ligate chromatin (Paakinaho et al. 2017). It is therefore possible to speculate that unliganded receptor-binding events may occur on permissive chromatin in open conformation and that this can lead to aberrant activation of oncogenic transcription if key binding sites reside in open conformation. This is a plausible scenario in CRPCs with AR overexpression, in which the excess of the receptor in a low-androgen micromilieu is translocated into the nucleus. Concordantly, a recent report has shown that constitutively active AR variants (AR-Vs) can bind to open chromatin and promote abiraterone-resistant growth ( $\mathrm{He}$ et al. 2018).

The DNA-binding domains of GR, PR and AR are highly similar, with nearly identical residues involved in contacting DNA and high similarity of their dimerization interfaces (Claessens et al. 2013). DNA motifs bound by these steroid receptors are also similar, but for the AR, it has been demonstrated that the DNA sequence of the response elements (the DNA-binding motif) is not as stringent as for other steroid receptors, which is a special feature of AR that sets it apart from other steroid receptors (Sahu et al. 2014).

Steroid receptors' interaction with the chromatin seems to be a very specific process in physiological condition (reviewed in Pihlajamaa et al. 2015), which may reflect a tightly organized chromatin structure allowing only specific chromatin-binding events. However, in the context of deregulated chromatin structure as in advanced PC, the functional steps that follow activation of steroid receptors leading to, for example, AR binding to chromatin, can be influenced by the many highly variable and context-specific factors discussed previously. The same pioneer factors and coregulators can interact with several steroid receptors, and multiple receptors can bind to the same cis-elements on the chromatin. These processes ensure distinct tissue- and cancer-type-specific gene expression profiles. An open chromatin environment that permits TFs to bind creates some ground for TFs to compete for chromatin binding. Interestingly, the competition for chromatin binding between these TFs is less well studied, but an intrinsic interplay has been shown for steroid receptors specifically (Pihlajamaa et al. 2015). Therefore, overexpression of one or more specific $\mathrm{TF}(\mathrm{s})$, or overexpression of the repertoire of coregulators and pioneer factors, can result in deregulated cistromes and transcriptome reprogramming in cancer cells as a result of competitive binding.

Gene transcriptional activation can occur by the cooperative action of AR with other TFs such as ETS or HOXB13 bound to DNA at adjacent sites (Ratnam et al. 2013). It is not clear in this context whether the AR would act as cofactor or directly dictate TF binding. In our previous study, a more than three-fold higher number of open chromatin sites was found in CRPC compared to primary PC or BPH (Urbanucci et al. 2017). Therefore, the increased open chromatin observed in CRPCs creates additional possibilities for other TFs to bind chromatin and increases the likelihood for activation of oncogenic transcriptional programs. For example, we have shown that a core set of ARBSs was conserved during all phases of the cell cycle, but other ARBSs were deputed to drive a transcriptional program specific in each cell cycle phase (McNair et al. 2017). Deregulation of these AR-binding dynamics in the context of AR overexpression pushes toward faster cell cycle, as demonstrated by studies of PC transcriptomics (Waltering et al. 2009) and by the fact that the composition of androgen-responsive genes changes during disease progression (Lee et al. 2013).

An example of TFs re-activated and overexpressed in CRPC that mediate resistance to therapy is the GR (Isikbay et al. 2014, Puhr et al. 2018). FOXA1 depletion was shown to lead to an increased chromatin binding of AR and decreased GR binding in PC models (Sahu et al. 2011), which confirms a context-dependent pioneering function of FOXA1, but also potentially explains lowered expression 
of GR in a subtype of primary tumors expressing low levels of FOXA1. Shah and colleagues found that GR polycombmediated silencing in primary PC was due to an ARBS at the upstream enhancer of the $G R$ gene. Re-expression of GR in ADT-resistant tumors was mediated by the activity of BRD4, a BRD, member of the subgroup of proteins called bromodomain and extraterminal (BET) proteins (reviewed in Urbanucci \& Mills 2018). Inhibition of BRD4, using a BET inhibitor (BETi), was able to restore sensitivity to enzalutamide in these tumors (Shah et al. 2017). BRD4 is also a HAT that evicts nucleosomes from chromatin (Devaiah et al. 2016). Shah and colleagues also demonstrated that GR overexpression-mediated antiandrogen resistance is dependent on BRDs (Shah et al. 2017), which in this context, indirectly provides evidence for increased chromatin accessibility in these tumors.

These studies support the idea that in an open chromatin environment, TFs can be interchangeably exploitable for CRPCs to adapt transcription to cellular stress and treatment, and that dedifferentiation and stemness can be a product of such TF interchangeability in advanced tumors.

\section{Transcription factor binding and chromatin in neuroendocrine prostate cancer}

With the clinical implementation of novel AR-directed therapies (e.g., abiraterone and enzalutamide) for patients with metastatic CRPC, the prevalence of AR-negative CRPC variants has increased (Beltran et al. 2016, Bluemn et al. 2017, Aggarwal et al. 2018). These therapy-resistant CRPC subtypes generally show low dependence on AR signaling, a different transcriptome and mutational landscape from conventional CRPC adenocarcinomas, and are anticipated to become more prevalent with more widespread use and implementation of novel AR-targeted therapies. CRPC is normally defined as adenocarcinoma in the sense that harbors the typical features of epithelial differentiation with expression of luminal genes and are frequently still reliant on sustained AR signaling. Treatment-related neuroendocrine CRPCs (t-NEPCs), on the other hand, are emerging subtypes of CRPC characterized by stem cell/ basal-like features, neuroendocrine differentiation and are frequently AR negative (Ellis \& Loda 2015).

The chromatin structure of t-NEPCs has not yet been extensively studied, and it will be intriguing to understand whether the increased chromatin opening observed in CRPC is maintained or even enhanced in t-NEPC and how this influences the activity of characterized TFs in this PC subtype.
t-NEPCs have been reported to harbor alterations in RB1 and TP53 more frequently than CRPC adenocarcinomas yet are believed to arise through clonal divergent evolution (Beltran et al. 2016). Interestingly, RB1 loss has been shown to lead to cistrome reprogramming of other TFs in CRPC (McNair et al. 2018) while concomitant functional loss of p53 and RB1 was shown to drive upregulation of chromatin modifying factors such as the polycomb repressive complex 2 (PRC2) catalytic subunit enhancer of zeste homolog 2 (EZH2) and SRY (sexdetermining region Y)-box 2 (SOX2), thereby facilitating epigenetic reprogramming and emergence of t-NEPC (Ku et al. 2017, Mu et al. 2017). The Yamanaka factor SOX2 is involved in lineage plasticity and resistance to ADT (Lee et al. 2018) and was shown to be markedly elevated in two-thirds of t-NEPC patient samples (Beltran et al. 2016).

Also overexpression of N-MYC has been found to promote tumor characteristics reminiscent of clinical t-NEPC, and N-MYC mRNA is upregulated in clinical t-NEPC tumors (Beltran et al. 2016, Dardenne et al. 2016, Lee et al. 2016). Dardenne and colleagues showed that N-MYC overexpression-driven NEPC development in mouse and cell line models was associated with suppression of AR signaling (Dardenne et al. 2016). They also performed ChIP experiments that suggested that $\mathrm{N}$-MYC could bind to enhancer regions in the absence of active AR. Interestingly, binding of N-MYC to these AREs was stabilized by DHT supplementation (Dardenne et al. 2016). We recently showed that Aurora kinase A (AURKA), which is commonly overexpressed in AR-negative t-NEPC (Beltran et al. 2011), is also commonly altered in CRPC (Kivinummi et al. 2017). Interestingly, AURKA has been shown to interact and stabilize the transcriptional activity of N-MYC in neuroblastoma (Brockmann et al. 2013), suggesting that binding of N-MYC can occur as a consequence of the activation of different signaling pathways.

N-MYC has been found to complex with and promote the activity of EZH2 (Dardenne et al. 2016). Earlier data supported the notion that EZH2 overexpression drives emergence of CRPC in a PRC2-independent manner, thus independently of its histone methyltransferase activity (Xu et al. 2012). Recently, using a ChIP-seq approach, EZH2 was shown to occupy the $A R$ promoter and act as a transcriptional activator for $A R$ transcription (Kim et al. 2018), suggesting that its overexpression in t-NEPCs compared to CRPC adenocarcinomas (Clermont et al. 2015) may actually be associated also with its increased coactivator-function rather than its function in deposition of the repressive H3K27me3 mark. 
Clermont et al. showed that several histone-modifying enzymes with chromatin remodeling activity, including CBX2 and EZH2, were upregulated in t-NEPCs as compared to CRPC adenocarcinomas (Clermont et al. 2015). Furthermore, they showed that polycomb group proteins with DNA methyltransferase (DNMT) activity were also aberrantly expressed in t-NEPC (Clermont et al. 2015).

Together with evidence that the transcriptomes of t-NEPC subtypes are so intrinsically different from, for example, CRPCs (Robinson et al. 2015, Beltran et al. 2016, Dardenne et al. 2016), the above-mentioned studies suggest that reconfiguration of the TF complexes at the regulatory regions of target genes can drive both $\mathrm{PC}$ progression to CRPC and also the development of t-NEPC. This may possibly explain how some overexpressed TFs such as N-MYC can dominate the transcriptional output of these latter tumor subtypes through chromatin remodeling activity.

\section{Bromodomain-containing proteins and chromatin reprogramming in prostate cancer}

BRDs are a family of epigenetic reader proteins, and many BRDs are aberrantly expressed in PC (reviewed in Urbanucci \& Mills 2018). BRDs are able to recognize acetylated histones, but often have additional chromatin remodeling functions. Moreover, they make out a part of multi-subunit chromatin remodeling complexes. Recent advances in the understanding and appreciation of BRDs in cancer have prompted investigations into whether BRD inhibition can be exploited clinically. In fact, targeting BRDs is currently being evaluated as a major therapeutic strategy in the treatment of blood cancers and solid tumors, including PC (reviewed in Urbanucci \& Mills 2018).

BRDs have been shown to modulate key transcriptional programs during cancer progression (Fu et al. 2015). For example, the BRD protein BRG1, encoded by SMARCA4, is an ATPase subunit of the SWI/SNF complex that mobilizes nucleosomes (Griffin et al. 2008, Medina \& Sanchez-Cespedes 2008). Ding et al. recently showed that increased BRG1 expression in PTEN-deficient PC cells led to chromatin remodeling into a configuration that drove a protumorigenic transcriptome (Ding et al. 2019). They employed ATAC-seq in PTEN-deficient 22Rv1 PC cells to show that BRG1 knockdown led to a $60 \%$ reduction in open chromatin regions compared to BRG1-intact cells (Ding et al. 2019). They also showed that high BRG1 expression was associated with worse outcomes in PC patients with low PTEN expression (Ding et al. 2019). Moreover, they demonstrated in preclinical models of PTEN-knockout mice that PC tumors become addicted to BRG1 (Ding et al. 2019). The work by Ding and colleagues suggests that BRG1 may be a promising target in PTENdeficient PCs.

Similar to BRG1, BET BRDs such as BRD2 and BRD4 have been implicated in chromatin remodeling processes. Overexpression of BRD4 in vivo has been associated with chromatin de-compaction and nucleosome eviction (Devaiah et al. 2016), and BRD4 has been reported to transcriptionally co-activate the AR (Asangani et al. 2014). Similar involvement in nucleosome eviction has been reported for BRD2 (Surface et al. 2016).

BET proteins have previously been shown to be of therapeutic relevance in treatment of CRPCs (Asangani et al. 2014). Having established that the activity of AR coregulators play a role in driving AR-mediated chromatin opening, our group focused on understanding whether BRDs could be responsible for the generalized chromatin opening mediated by AR in CRPC (Urbanucci et al. 2017). Employing FAIRE, we could show that the enhanced local chromatin accessibility in AR-overexpressing cells could be reversed by treatment with sub-toxic concentrations of the bromodomain inhibitor JQ1 (Urbanucci et al. 2017) that predominantly targets BET proteins (Filippakopoulos et al. 2010). Concomitantly, the most upregulated class of genes after treatment with JQ1 were histone genes and genes encoding chromatin structure-associated proteins (Urbanucci et al. 2017), which is consistent with the effect of chromatin re-compaction elicited in these cells by the treatment. We selected three key BRDs, namely BRD2, BRD4 and ATPase family, AAA domain-containing 2 (ATAD2), for knockdown experiments followed by FAIRE at regulatory regions of AR target genes to test which of these BRDs had the most pronounced impact on local chromatin opening. Knockdown of all three proteins separately influenced chromatin opening at selected loci. However, the effects on local chromatin remodeling following single knockdown seemed to be locus specific. This suggested that these proteins can act differently on different genomic loci and that their functions may be redundant or that compensatory mechanisms exist (Urbanucci et al. 2017).

ATAD2 has been shown to be a co-activator of both $\mathrm{AR}$ and c-MYC in hormone-responsive human breast and prostate tumors (Ciro et al. 2009). The role of ATAD2 as a regulator of chromatin dynamics has been extensively studied in yeast (Cattaneo et al. 2014): It is implicated 
in chromatin structure maintenance and is capable of reading acetyl modifications on histone residues. Koo and colleagues showed that ATAD2 is highly expressed in replicating PC cells, and ATAD2 expression correlated with the expression of cell cycle and DNA replication genes that have overlapping functions in meiosis and tumor progression (Koo et al. 2016). Moreover, ATAD2 has been reported to be important in sustaining specific gene expression programs via regulating chromatin opening in embryonic stem cells (Morozumi et al. 2016). In particular, Morozumi et al. found that ATAD2 sustained open chromatin states and ATAD2 depletion desensitized cells to micrococcal nuclease (MNase) treatment. Morozumi et al. also found that histone acetylation guides ATAD2 to chromatin, resulting in an overall increase in chromatin accessibility (Morozumi et al. 2016).

In agreement with a previous study (Zou et al. 2009), we found that ATAD2 was regulated by androgens (Urbanucci et al. 2017). In addition, we showed that AR-overexpressing cells expressed higher levels of ATAD2 in androgen depletion-challenged PC cells (Urbanucci et al. 2017). We identified also BRD2 as an androgenregulated gene and BRD2 protein levels were elevated in AR-overexpressing cells (Urbanucci et al. 2017). Although BRD4 protein levels were elevated in AR-overexpressing cells, we could not observe a significant transcriptional regulation of BRD4 by androgens (Urbanucci et al. 2017).

We also investigated the clinical value of the aforementioned BRDs as prognostic biomarkers in independent PC patient cohorts (Urbanucci et al. 2017). We determined that one of the isoforms of BRD4, the BRD4 long isoform, BRD2 and ATAD2 were all overexpressed in CRPC tissues compared to primary tumors. Moreover, high BRD2 expression in primary tumors was associated with shorter PC-specific survival (Urbanucci et al. 2017). More recently, the nuclear BRD4 protein level was confirmed to increase following castration resistance in longitudinally matched tumor samples collected pre and post treatment (Welti et al. 2018). We also found that high expression of ATAD2 was positively associated with biochemical recurrence on a cohort of 10,000 patients (Urbanucci et al. 2017).

These studies demonstrate that BRDs are important tissue biomarkers, which can molecularly define subtypes of PC characterized by high chromatin alterations and responsiveness to BRD inhibitors.

Asangani et al. have demonstrated the efficacy of BETi in reducing viability of PC cells (Asangani et al. 2014), and later they showed that BETi could reduce growth of enzalutamide-resistant PC cells as well
(Asangani et al. 2016). Knockdown of BRD4 had the strongest effect on PC cell viability in our models of AR overexpression (Urbanucci et al. 2017). We also showed that BETi in combination with enzalutamide had an additive inhibitory effect and that this effect was stronger in AR-overexpressing cells compared to 'naïvely' AR-expressing cells. This suggested that PC cells resistant to enzalutamide still rely on mechanisms mediated by both AR and BRDs for their survival. For example, we have reported that several CRPC-associated genes, such as UBE2C, HOXB13, CAMKK2 and AURKA, were repressed by JQ1 treatment, and the chromatin at regulatory regions of these genes was re-compacted (Urbanucci et al. 2017). It is still uncertain whether bromodomain activity favors expression of key genes important for enzalutamide resistance, however. AURKA has been identified as an important driver of t-NEPC arising from treatment with novel antiandrogens such as enzalutamide (Mosquera et al. 2013), and we have shown that it is a target of both BRDs (Urbanucci et al. 2017) and AR (Kivinummi et al. 2017) activity. We have also shown that AURKA was overexpressed in CRPC (Kivinummi et al. 2017), and interestingly, AURKA has been shown to sustain the expression and activity of AR splice variants (Jones et al. 2017). This suggests that BRD inhibition may still be an effective therapeutic strategy in combination with other agents in t-NEPCs that overexpress AURKA. Although Wyce and colleagues showed that BETi was unable to impact tumor growth in a PDX model displaying NEPC characteristics (LuCaP 145.2) (Wyce et al. 2013), the stochasticity of the evolution of these particular classes of tumors and their high heterogeneity (Aggarwal et al. 2018, Lee et al. 2018) suggests that BETi should be evaluated in more preclinical t-NEPC models. Successful identification of the subset of t-NEPC tumors likely to respond to bromodomain inhibition may have large implications for the treatment of this increasingly prevalent PC subtype.

In summary, these data suggest that the increased expression of BRDs in CRPCs may be a driving force for the increased chromatin relaxation observed in these tumors, and consequently, for their increased transcriptional plasticity.

\section{Clinical implications}

Chromatin deregulation and relaxation result in aberrant transcriptional reprogramming, cell plasticity and an increased chance to activate oncogenic pathways that promote therapy resistance. The possibility to target a 
deregulated chromatin structure, or more generally, a deregulated epigenome, should be regarded as a way to tackle the acquired increase in plasticity that renders PC cells able to adapt to different therapeutic approaches. In PC, combination of existing therapies with bromodomain inhibition, and with inhibition of proteasome and autophagy in transcriptionally overdosed PCs could be therapeutically beneficial (Chude \& Amaravadi 2017). For example, BETi in combination with drugs such as enzalutamide may be therapeutically beneficial by reverting the chromatin structure toward a more differentiated state, and clinical trials investigating these treatment strategies are ongoing. It can be speculated that such epigenomic re-differentiation may help in maintaining AR dependency and continued efficacy of AR-targeted therapies while preventing further lineage alterations.

Mechanisms of resistance to BETi have been already reported (Rathert et al. 2015) and are probably due to compensatory mechanisms still linked to chromatin reprogramming which are capable of activating alternative oncogenic pathways (Pawar et al. 2018). Therefore, targeting a deregulated chromatin structure with BETi is an attractive therapeutic strategy as it is plausible that chromatin deregulation is a reversible mechanism. In this context, in PC, the epigenetic 'fluidity' and tendency of the chromatin to be in relaxed structure could be a liability if targeted intermittently to prolong the duration of the effect and delay the emergence of resistance. This epigenetic 'fluidity' can potentially explain the positive results demonstrated by the use of bipolar androgen therapy (BAT) (Teply \& Antonarakis 2016, Teply et al. 2018), intermittent androgen deprivation therapy (Hussain et al. 2016, Abrahamsson 2017), and, with due precautions, also supra-physiological androgen therapy (Mohammad et al. 2017).

High androgen levels leads to LSD1/AR-mediated $A R$ gene suppression in PC, but castrate levels of androgens leads to upregulation of the AR (Cai et al. 2011, Coutinho et al. 2016). This fundamental process is at the base of PCs' addiction to AR signaling. Well-controlled experiments in preclinical models have shown that AR upregulation is the result of adaptive autoregulation of the AR to low androgen levels (Isaacs et al. 2012). As we have discussed that AR upregulation is associated with increased chromatin deregulation, preventing this step with repeated cycles of androgen deprivation and supplementation, which in fact affects the AR level (Isaacs et al. 2017), may also delay the emergence of chromatin deregulation and cell plasticity. This can explain why in asymptomatic men with metastatic CRPC, BAT was able to resensitize tumors to enzalutamide treatment in most patients undergoing rechallenge (Teply et al. 2018).

Molecular probes for different BRD targets are now being clinically tested in PC patients for exploiting epigenetic alterations (Fernandez-Salas et al. 2016, Baumgart \& Haendler 2017, Urbanucci \& Mills 2018). Whether selection of patients with high chromatin deregulation will respond better to these therapeutic approaches/regimens remains to be investigated. To this end, the assessment of stratification biomarkers, such as genetic signatures or tissue biomarkers should be evaluated in clinical trials (Cieślik \& Chinnaiyan 2018).

Others and we have showed that BRDs such as BRD4, BRD2 and ATAD2 are mediators of the increased chromatin accessibility observed in CRPC, and are prognostic tissue markers overexpressed in CRPC (Urbanucci et al. 2017, Welti et al. 2018). Therefore, BRDs can be used as readout of an altered epigenome. Towards this end, we have generated BROMO-10, a ten-gene signature that proxies the chromatin remodeling activity and chromatin status in PC tumors (Urbanucci et al. 2017). Thus, BROMO-10 could be used for selecting patients with high AR activity likely to benefit from BET-targeted therapies. BROMO-10 was retrospectively able to identify also intermediaterisk PC (i.e. Gleason score 7) patients with a high risk of early progression (Gerhauser et al. 2018), which indicates that these tumors are likely driven by a 'fluid' chromatin structure and can be triggered by therapeutic pressure to progress.

Ultimately, as BET inhibitors have been proven efficacious in a number of other pathologies, its effect on chromatin accessibility should be considered as a major mechanism of action not only in PC, but also in a cellspecific manner in diseases of other tissues as well.

\section{Future perspectives}

Studies on chromatin structure evolution enforced by therapeutic pressure are lacking. For example, it remains to be shown whether the chromatin structure is further altered in t-NEPCs as compared to CRPC adenocarcinomas. Although several cohorts contain patients with these disease entities, they lack longitudinal biopsies and can thus not infer direct proof of tumor evolution as opposed to selection. A genomic study on longitudinal biopsies from tumors before and after t-NEPC emergence is 
ongoing (Aggarwal et al. 2018) and with the appropriate analytical tools, this study could show whether further chromatin relaxation occurs upon lineage plasticitydriven AR-targeted therapy resistance.

Structural variations are found in regions of open chromatin, which include ARBSs (Gerhauser et al. 2018). Overall, PC has a low somatic mutational burden compared to other cancers, yet has a tendency towards accumulating structural alterations (Barbieri et al. 2012, Grasso et al. 2012, Zehir et al. 2017). The most frequent structural alteration is the TMPRSS2:ERG gene fusion, which can be detected in more than half of clinically localized and metastatic PC cases (Tomlins et al. 2005, Taylor et al. 2010). Interestingly, this and other fusion genes have been shown to involve androgen-regulated genes (Rubin et al. 2011), suggesting that chromatin structure is involved in inducing proximity between the regulatory regions of the AR-target genes and the fusion partner genes. In this context, one of the key questions that remains to be addressed is whether it will be possible to characterize the earliest tumorigenic chromatin alterations during initiation of PC. This has been done for DNA methylation (Massie et al. 2017) but to a lesser extent for chromatin structure. Chromatin accessibility has been used to identify binding of TFs and genomic regulatory elements, and it is used together with information on binding of TFs such as $\mathrm{AR}$ to prioritize disease-associated SNPs that are not within coding regions. We have shown that chromatin regions bound by BRD4 can identify risk SNPs that achieved statistical significance in genome-wide association studies (GWAS) for prostate, breast and lung cancer in a tissue/disease-specific manner (Zuber et al. 2017). This, together with the evidence that BRDs are upregulated already in primary PCs possibly implies a role of BRDs in early deregulation of chromatin structure and tumor initiation, which should be further explored.

Furthermore, the chromatin structure may reflect the metabolic status of a cell as it depends on the availability of many metabolites in order to maintain the make-up of histone modifications (Schvartzman et al. 2018). Therefore, it will be increasingly important to understand the link between metabolic perturbations occurring in CRPC and the effects that these elicit on the chromatin structure (Li et al. 2018). The metabolite addiction to, for example, acetyl groups for HAT activity and transcription in CRPC may ultimately rely on deregulation of metabolic pathways (Kinnaird et al. 2016), which should be better characterized to understand their effect on chromatin remodeling.

2019 Society for Endocrinology Published by Bioscientifica Ltd. Printed in Great Britain

\section{Conclusions}

In this review we have collected evidence of the AR overexpression-mediated positive feedback loop that boosts the expression of many chromatin-associated proteins, including BRDs, that act to increase the chromatin accessibility of AR and other TFs in CRPCs.

AR overexpression-driven chromatin structural alterations can be thought of as a key determinant feature of PC progression, which leads to activation of several adaptive oncogenic transcriptional responses and drive tumor growth and therapy resistance: a phenomenon of epigenetically driven adaptation to therapeutic pressure.

We are now beginning to understand how the chromatin structure can be modulated to reprogram PC cells. More work is needed to understand how the chromatin structure and the higher order conformation of the chromatin in the nucleus is organized. This knowledge will help us understand and predict events driving PC development and progression. Finally, targeting pathways involved in chromatin reprogramming arises as a compelling strategy for preventing and possibly reverting the therapy-driven increase in plasticity of PC cells.

\section{Declaration of interest}

The authors declare that there is no conflict of interest that could be perceived as prejudicing the impartiality of this review.

\section{Funding}

A $U$ is supported by the Institute for Cancer Genetics and Informatics and by the Institute for Cancer Research at the Department of Tumor Biology within the Oslo University Hospital thanks to the Norwegian Cancer Society (grant \# 198016-2018). He is also a guest researcher at the Norwegian Centre for Molecular Medicine supported by the Norwegian Research Council (grant number \# 187615). P R B is supported by the Institute for Cancer Research at the Department of Tumor Biology within the Oslo University Hospital, with a PhD grant from the South-Eastern Norway Regional Health Authority (grant number 2016043).

\section{Acknowledgements}

The authors apologize for research that they were not able to cite. They thank Prof. Ian G Mills for the helpful discussion and critical reading of the manuscript.

\section{References}

Abrahamsson PA 2017 Intermittent androgen deprivation therapy in patients with prostate cancer: connecting the dots. Asian Journal of Urology 4 208-222. (https://doi.org/10.1016/j.ajur.2017.04.001)

Aggarwal R, Huang J, Alumkal JJ, Zhang L, Feng FY, Thomas GV, Weinstein AS, Friedl V, Zhang C, Witte ON, et al. 2018 Clinical and genomic characterization of treatment-emergent small-cell 
neuroendocrine prostate cancer: a multi-institutional prospective study. Journal of Clinical Oncology 36 2492-2503. (https://doi. org/10.1200/JCO.2017.77.6880)

Ahmadiyeh N, Pomerantz MM, Grisanzio C, Herman P, Jia L, Almendro V, He HH, Brown M, Liu XS, Davis M, et al. 2010 8q24 prostate, breast, and colon cancer risk loci show tissue-specific longrange interaction with MYC. PNAS 107 9742-9746. (https://doi. org/10.1073/pnas.0910668107)

Andreu-Vieyra C, Lai J, Berman BP, Frenkel B, Jia L, Jones PA \& Coetzee GA 2011 Dynamic nucleosome-depleted regions at androgen receptor enhancers in the absence of ligand in prostate cancer cells. Molecular and Cellular Biology 31 4648-4662. (https://doi. org/10.1128/MCB.05934-11)

Antonarakis ES, Lu C, Wang H, Luber B, Nakazawa M, Roeser JC, Chen Y, Mohammad TA, Chen Y, Fedor HL, et al. 2014 AR-V7 and resistance to enzalutamide and abiraterone in prostate cancer. New England Journal of Medicine 371 1028-1038. (https://doi.org/10.1056/ NEJMoa1315815)

Arora VK, Schenkein E, Murali R, Subudhi SK, Wongvipat J, Balbas MD, Shah N, Cai L, Efstathiou E, Logothetis C, et al. 2013 Glucocorticoid receptor confers resistance to antiandrogens by bypassing androgen receptor blockade. Cell 155 1309-1322. (https://doi.org/10.1016/j. cell.2013.11.012)

Asangani IA, Dommeti VL, Wang X, Malik R, Cieslik M, Yang R, EscaraWilke J, Wilder-Romans K, Dhanireddy S, Engelke C, et al. 2014 Therapeutic targeting of BET bromodomain proteins in castrationresistant prostate cancer. Nature 510 278-282. (https://doi. org/10.1038/nature13229)

Asangani IA, Wilder-Romans K, Dommeti VL, Krishnamurthy PM, Apel IJ, Escara-Wilke J, Plymate SR, Navone NM, Wang S, Feng FY, et al. 2016 BET bromodomain inhibitors enhance efficacy and disrupt resistance to AR antagonists in the treatment of prostate cancer. Molecular Cancer Research 14 324-331. (https://doi. org/10.1158/1541-7786.MCR-15-0472)

Audia JE \& Campbell RM 2016 Histone modifications and cancer. Cold Spring Harbor Perspectives in Biology 8 a019521. (https://doi. org/10.1101/cshperspect.a019521)

Bannister AJ \& Kouzarides T 2011 Regulation of chromatin by histone modifications. Cell Research 21 381-395. (https://doi.org/10.1038/ cr.2011.22)

Barbieri CE, Baca SC, Lawrence MS, Demichelis F, Blattner M, Theurillat JP, White TA, Stojanov P, Van Allen E, Stransky N, et al. 2012 Exome sequencing identifies recurrent SPOP, FOXA1 and MED12 mutations in prostate cancer. Nature Genetics 44 685-689. (https://doi.org/10.1038/ng.2279)

Barfeld SJ, Urbanucci A, Itkonen HM, Fazli L, Hicks JL, Thiede B, Rennie PS, Yegnasubramanian S, DeMarzo AM \& Mills IG 2017 c-Myc antagonises the transcriptional activity of the androgen receptor in prostate cancer affecting key gene networks. EBioMedicine 18 83-93. (https://doi.org/10.1016/j.ebiom.2017.04.006)

Baumgart SJ \& Haendler B 2017 Exploiting epigenetic alterations in prostate cancer. International Journal of Molecular Sciences 181017. (https://doi.org/10.3390/ijms18051017)

Beltran H, Rickman DS, Park K, Chae SS, Sboner A, MacDonald TY, Wang Y, Sheikh KL, Terry S, Tagawa ST, et al. 2011 Molecular characterization of neuroendocrine prostate cancer and identification of new drug targets. Cancer Discovery 1 487-495. (https://doi. org/10.1158/2159-8290.CD-11-0130)

Beltran H, Prandi D, Mosquera JM, Benelli M, Puca L, Cyrta J, Marotz C, Giannopoulou E, Chakravarthi BV, Varambally S, et al. 2016 Divergent clonal evolution of castration-resistant neuroendocrine prostate cancer. Nature Medicine 22 298-305. (https://doi. org/10.1038/nm.4045)

Bernard D, Pourtier-Manzanedo A, Gil J \& Beach DH 2003 Myc confers androgen-independent prostate cancer cell growth. Journal of Clinical Investigation 112 1724-1731. (https://doi.org/10.1172/JCI19035)
Bluemn EG, Coleman IM, Lucas JM, Coleman RT, Hernandez-Lopez S, Tharakan R, Bianchi-Frias D, Dumpit RF, Kaipainen A, Corella AN, et al. 2017 Androgen receptor pathway-independent prostate cancer is sustained through FGF signaling. Cancer Cell 32 474.e6-489.e6. (https://doi.org/10.1016/j.ccell.2017.09.003)

Brockmann M, Poon E, Berry T, Carstensen A, Deubzer HE, Rycak L, Jamin Y, Thway K, Robinson SP, Roels F, et al. 2013 Small molecule inhibitors of aurora-a induce proteasomal degradation of $\mathrm{N}$-myc in childhood neuroblastoma. Cancer Cell 24 75-89. (https://doi. org/10.1016/j.ccr.2013.05.005)

Buenrostro JD, Giresi PG, Zaba LC, Chang HY \& Greenleaf WJ 2013 Transposition of native chromatin for fast and sensitive epigenomic profiling of open chromatin, DNA-binding proteins and nucleosome position. Nature Methods 10 1213-1218. (https://doi.org/10.1038/ nmeth.2688)

Cai C, He HH, Chen S, Coleman I, Wang H, Fang Z, Chen S, Nelson PS, Liu XS, Brown M, et al. 2011 Androgen receptor gene expression in prostate cancer is directly suppressed by the androgen receptor through recruitment of lysine-specific demethylase 1. Cancer Cell 20 457-471. (https://doi.org/10.1016/j.ccr.2011.09.001)

Carlberg C \& Seuter S 2010 Dynamics of nuclear receptor target gene regulation. Chromosoma 119 479-484. (https://doi.org/10.1007/ s00412-010-0283-8)

Cattaneo M, Morozumi Y, Perazza D, Boussouar F, Jamshidikia M, Rousseaux S, Verdel A \& Khochbin S 2014 Lessons from yeast on emerging roles of the ATAD2 protein family in gene regulation and genome organization. Molecules and Cells 37 851-856. (https://doi. org/10.14348/molcells.2014.0258)

Cedar H \& Bergman Y 2012 Programming of DNA methylation patterns. Annual Review of Biochemistry 81 97-117. (https://doi.org/10.1146/ annurev-biochem-052610-091920)

Center MM, Jemal A, Lortet-Tieulent J, Ward E, Ferlay J, Brawley O \& Bray F 2012 International variation in prostate cancer incidence and mortality rates. European Urology 61 1079-1092. (https://doi. org/10.1016/j.eururo.2012.02.054)

Chang AK \& Wu H 2012 The role of AIB1 in breast cancer. Oncology Letters 4 588-594. (https://doi.org/10.3892/ol.2012.803)

Chen CD, Welsbie DS, Tran C, Baek SH, Chen R, Vessella R, Rosenfeld MG \& Sawyers CL 2004 Molecular determinants of resistance to antiandrogen therapy. Nature Medicine $1033-39$. (https://doi.org/10.1038/nm972)

Chen Z, Zhang C, Wu D, Chen H, Rorick A, Zhang X \& Wang Q 2011 Phospho-MED1-enhanced UBE2C locus looping drives castrationresistant prostate cancer growth. EMBO Journal 30 2405-2419. (https://doi.org/10.1038/emboj.2011.154)

Chen Y, Chi P, Rockowitz S, Iaquinta PJ, Shamu T, Shukla S, Gao D, Sirota I, Carver BS, Wongvipat J, et al. 2013 ETS factors reprogram the androgen receptor cistrome and prime prostate tumorigenesis in response to PTEN loss. Nature Medicine 19 1023-1029. (https://doi. org/10.1038/nm.3216)

Chen Z, Wu D, Thomas-Ahner JM, Lu C, Zhao P, Zhang Q Geraghty C, Yan PS, Hankey W, Sunkel B, et al. 2018 Diverse AR-V7 cistromes in castration-resistant prostate cancer are governed by HoxB13. PNAS 115 6810-6815 AR-V7. (https://doi.org/10.1073/ pnas.1718811115)

Chude CI \& Amaravadi RK 2017 Targeting autophagy in cancer: update on clinical trials and novel inhibitors. International Journal of Molecular Sciences 18 1279. (https://doi.org/10.3390/ijms18061279)

Cieślik M \& Chinnaiyan AM 2018 Cancer transcriptome profiling at the juncture of clinical translation. Nature Reviews Genetics 19 93-109. (https://doi.org/10.1038/nrg.2017.96)

Ciro M, Prosperini E, Quarto M, Grazini U, Walfridsson J, McBlane F, Nucifero P, Pacchiana G, Capra M, Christensen J, et al. 2009 ATAD2 is a novel cofactor for MYC, overexpressed and amplified in aggressive tumors. Cancer Research 69 8491-8498. (https://doi. org/10.1158/0008-5472.CAN-09-2131) (c) 2019 Society for Endocrinology Published by Bioscientifica Ltd. Printed in Great Britain 
Claessens F, Clinckemalie L, Christine H, Spans L, Dubois V, Laurent M, Boonen S \& Vanderschueren D 2013 Selective and classical androgen response elements in androgen-regulated gene expression. In AndrogenResponsive Genes in Prostate Cancer: Regulation, Function and Clinical Applications. Ed. Z Wang. New York, NY, USA: Springer, pp. 13-27.

Clermont PL, Lin D, Crea F, Wu R, Xue H, Wang Y, Thu KL, Lam WL, Collins CC, Wang Y, et al. 2015 Polycomb-mediated silencing in neuroendocrine prostate cancer. Clinical Epigenetics 7 40. (https://doi. org/10.1186/s13148-015-0074-4)

Comuzzi B, Nemes C, Schmidt S, Jasarevic Z, Lodde M, Pycha A, Bartsch G, Offner F, Culig Z \& Hobisch A 2004 The androgen receptor co-activator CBP is up-regulated following androgen withdrawal and is highly expressed in advanced prostate cancer. Journal of Pathology 204 159-166. (https://doi.org/10.1002/ path.1609)

Corces MR, Granja JM, Shams S, Louie BH, Seoane JA, Zhou W, Silva TC, Groeneveld C, Wong CK, Cho SW, et al. 2018 The chromatin accessibility landscape of primary human cancers. Science $\mathbf{3 6 2}$ eaav1898. (https://doi.org/10.1126/science.aav1898)

Coutinho I, Day TK, Tilley WD \& Selth LA 2016 Androgen receptor signaling in castration-resistant prostate cancer: a lesson in persistence. Endocrine-Related Cancer 23 T179-T197. (https://doi. org/10.1530/ERC-16-0422)

Culig Z 2016 Androgen receptor coactivators in regulation of growth and differentiation in prostate cancer. Journal of Cellular Physiology 231 270-274. (https://doi.org/10.1002/jcp.25099)

Culig Z 2017 Molecular mechanisms of enzalutamide resistance in prostate cancer. Current Molecular Biology Reports 3 230-235. (https:// doi.org/10.1007/s40610-017-0079-1)

Dancy BM \& Cole PA 2015 Protein lysine acetylation by p300/CBP. Chemical Reviews 115 2419-2452. (https://doi.org/10.1021/ cr500452k)

Dardenne E, Beltran H, Benelli M, Gayvert K, Berger A, Puca L, Cyrta J, Sboner A, Noorzad Z, MacDonald T, et al. 2016 N-Myc induces an EZH2-mediated transcriptional program driving neuroendocrine prostate cancer. Cancer Cell 30 563-577. (https://doi.org/10.1016/j. ccell.2016.09.005)

Debes JD, Sebo TJ, Lohse CM, Murphy LM, Haugen DA \& Tindall DJ 2003 p300 in prostate cancer proliferation and progression. Cancer Research 63 7638-7640.

Devaiah BN, Case-Borden C, Gegonne A, Hsu CH, Chen Q Meerzaman D, Dey A, Ozato K \& Singer DS 2016 BRD4 is a histone acetyltransferase that evicts nucleosomes from chromatin. Nature Structural and Molecular Biology 23 540-548. (https://doi.org/10.1038/ nsmb.3228)

Ding Y, Li N, Dong B, Guo W, Wei H, Chen Q, Yuan H, Han Y, Chang H, Kan S, et al. 2019 Chromatin remodeling ATPase BRG1 and PTEN are synthetic lethal in prostate cancer. Journal of Clinical Investigation 129 759-773. (https://doi.org/10.1172/JCI123557)

Ellinger J, Kahl P, von der Gathen J, Rogenhofer S, Heukamp LC, Gutgemann I, Walter B, Hofstadter F, Buttner R, Muller SC, et al. 2010 Global levels of histone modifications predict prostate cancer recurrence. Prostate 70 61-69. (https://doi.org/10.1002/pros.21038)

Ellis L \& Loda M 2015 Advanced neuroendocrine prostate tumors regress to stemness. PNAS 112 14406-14407. (https://doi. org/10.1073/pnas.1519151112)

Fernandez-Salas E, Wang S \& Chinnaiyan AM 2016 Role of BET proteins in castration-resistant prostate cancer. Drug Discovery Today Technologies 19 29-38. (https://doi.org/10.1016/j.ddtec.2016.07.001)

Filippakopoulos P, Qi J, Picaud S, Shen Y, Smith WB, Fedorov O, Morse EM, Keates T, Hickman TT, Felletar I, et al. 2010 Selective inhibition of BET bromodomains. Nature 468 1067-1073. (https:// doi.org/10.1038/nature09504)

Fiorito E, Sharma Y, Gilfillan S, Wang S, Singh SK, Satheesh SV, Katika MR, Urbanucci A, Thiede B, Mills IG, et al. 2016 CTCF modulates estrogen receptor function through specific chromatin and nuclear matrix interactions. Nucleic Acids Research 44 10588-10602. (https://doi.org/10.1093/nar/gkw785)

Fu LL, Tian M, Li X, Li JJ, Huang J, Ouyang L, Zhang Y \& Liu B 2015 Inhibition of BET bromodomains as a therapeutic strategy for cancer drug discovery. Oncotarget 6 5501-5516. (https://doi.org/10.18632/ oncotarget.3551)

Fullwood MJ \& Ruan Y 2009 ChIP-based methods for the identification of long-range chromatin interactions. Journal of Cellular Biochemistry 107 30-39. (https://doi.org/10.1002/jcb.22116)

Gerhauser C, Favero F, Risch T, Simon R, Feuerbach L, Assenov Y, Heckmann D, Sidiropoulos N, Waszak SM, Hübschmann D, et al. 2018 Molecular evolution of early-onset prostate cancer identifies molecular risk markers and clinical trajectories. Cancer Cell 34996. e8-1011.e8. (https://doi.org/10.1016/j.ccell.2018.10.016)

Ghirlando R \& Felsenfeld G 2016 CTCF: making the right connections. Genes and Development 30 881-891. (https://doi.org/10.1101/ $\operatorname{gad} .277863 .116)$

Grasso CS, Wu YM, Robinson DR, Cao X, Dhanasekaran SM, Khan AP, Quist MJ, Jing X, Lonigro RJ, Brenner JC, et al. 2012 The mutational landscape of lethal castration-resistant prostate cancer. Nature $\mathbf{4 8 7}$ 239-243. (https://doi.org/10.1038/nature11125)

Griffin CT, Brennan J \& Magnuson T 2008 The chromatin-remodeling enzyme BRG1 plays an essential role in primitive erythropoiesis and vascular development. Development 135 493-500. (https://doi. org/10.1242/dev.010090)

Guo Y, Perez AA, Hazelett DJ, Coetzee GA, Rhie SK \& Farnham PJ 2018 CRISPR-mediated deletion of prostate cancer risk-associated CTCF loop anchors identifies repressive chromatin loops. Genome Biology 19 160. (https://doi.org/10.1186/s13059-018-1531-0)

Gurel B, Iwata T, Koh CM, Jenkins RB, Lan F, Van Dang C, Hicks JL, Morgan J, Cornish TC, Sutcliffe S, et al. 2008 Nuclear MYC protein overexpression is an early alteration in human prostate carcinogenesis. Modern Pathology 21 1156-1167. (https://doi. org/10.1038/modpathol.2008.111)

Haffner MC, Aryee MJ, Toubaji A, Esopi DM, Albadine R, Gurel B, Isaacs WB, Bova GS, Liu W, Xu J, et al. 2010 Androgen-induced TOP2B-mediated double-strand breaks and prostate cancer gene rearrangements. Nature Genetics 42 668-675. (https://doi. org/10.1038/ng.613)

Hauer MH, Seeber A, Singh V, Thierry R, Sack R, Amitai A, Kryzhanovska M, Eglinger J, Holcman D, Owen-Hughes T, et al. 2017 Histone degradation in response to DNA damage enhances chromatin dynamics and recombination rates. Nature Structural and Molecular Biology 24 99-107. (https://doi.org/10.1038/nsmb.3347)

Hawksworth D, Ravindranath L, Chen Y, Furusato B, Sesterhenn IA, McLeod DG, Srivastava S \& Petrovics G 2010 Overexpression of C-MYC oncogene in prostate cancer predicts biochemical recurrence. Prostate Cancer and Prostatic Diseases 13 311-315. (https://doi. org/10.1038/pcan.2010.31)

He HH, Meyer CA, Shin H, Bailey ST, Wei G, Wang Q, Zhang Y, Xu K, Ni M, Lupien M, et al. 2010 Nucleosome dynamics define transcriptional enhancers. Nature Genetics 42343 -347. (https://doi. org/10.1038/ng.545)

He HH, Meyer CA, Chen MW, Jordan VC, Brown M \& Liu XS 2012 Differential DNase I hypersensitivity reveals factor-dependent chromatin dynamics. Genome Research 22 1015-1025. (https://doi. org/10.1101/gr.133280.111)

He Y, Lu J, Ye Z, Hao S, Wang L, Kohli M, Tindall DJ, Li B, Zhu R, Wang L, et al. 2018 Androgen receptor splice variants bind to constitutively open chromatin and promote abiraterone-resistant growth of prostate cancer. Nucleic Acids Research 46 1895-1911. (https://doi.org/10.1093/nar/gkx1306)

Heemers HV \& Tindall DJ 2007 Androgen receptor (AR) coregulators: a diversity of functions converging on and regulating the AR transcriptional complex. Endocrine Reviews 28778 -808. (https://doi. org/10.1210/er.2007-0019) https://erc bioscientifica com

https://doi.org/10.1530/ERC-18-0579 (c) 2019 Society for Endocrinology Published by Bioscientifica Ltd. Printed in Great Britain 
Humphrey PA 2007 Diagnosis of adenocarcinoma in prostate needle biopsy tissue. Journal of Clinical Pathology 60 35-42. (https://doi. org/10.1136/jcp.2005.036442)

Hurtado A, Holmes KA, Ross-Innes CS, Schmidt D \& Carroll JS 2011 FOXA1 is a key determinant of estrogen receptor function and endocrine response. Nature Genetics 43 27-33. (https://doi. org/10.1038/ng.730)

Hussain M, Tangen C, Higano C, Vogelzang N \& Thompson I 2016 Evaluating intermittent androgen-deprivation therapy Phase III clinical trials: the devil is in the details. Journal of Clinical Oncology 34 280-285. (https://doi.org/10.1200/JCO.2015.62.8065)

Hveem TS, Kleppe A, Vlatkovic L, Ersvær E, Wæhre H, Nielsen B, Kjær MA, Pradhan M, Syvertsen RA, Nesheim JA, et al. 2016 Chromatin changes predict recurrence after radical prostatectomy. British Journal of Cancer 114 1243-1250. (https://doi.org/10.1038/ bjc.2016.96)

Isaacs JT, D'Antonio JM, Chen S, Antony L, Dalrymple SP, Ndikuyeze GH, Luo J \& Denmeade SR 2012 Adaptive auto-regulation of androgen receptor provides a paradigm shifting rationale for bipolar androgen therapy (BAT) for castrate resistant human prostate cancer. Prostate 72 1491-1505. (https://doi.org/10.1002/pros.22504)

Isaacs JT, Brennen WN \& Denmeade SR 2017 Rationale for bipolar androgen therapy (BAT) for metastatic prostate cancer. Cell Cycle $\mathbf{1 6}$ 1639-1640. (https://doi.org/10.1080/15384101.2017.1360645)

Isikbay M, Otto K, Kregel S, Kach J, Cai Y, Vander Griend DJ, Conzen SD \& Szmulewitz RZ 2014 Glucocorticoid receptor activity contributes to resistance to androgen-targeted therapy in prostate cancer. Hormones and Cancer 5 72-89. (https://doi.org/10.1007/s12672-0140173-2)

Jalava SE, Urbanucci A, Latonen L, Waltering KK, Sahu B, Janne OA, Seppala J, Lahdesmaki H, Tammela TL \& Visakorpi T 2012 Androgen-regulated miR-32 targets BTG2 and is overexpressed in castration-resistant prostate cancer. Oncogene 31 4460-4471. (https:// doi.org/10.1038/onc.2011.624)

Jariwala U, Cogan JP, Jia L, Frenkel B \& Coetzee GA 2009 Inhibition of AR-mediated transcription by binding of Oct1 to a motif enriched in AR-occupied regions. Prostate 69 392-400. (https://doi.org/10.1002/ pros.20893)

Jia L, Shen HC, Wantroba M, Khalid O, Liang G, Wang Q, Gentzschein E, Pinski JK, Stanczyk FZ, Jones PA, et al. 2006 Locuswide chromatin remodeling and enhanced androgen receptormediated transcription in recurrent prostate tumor cells. Molecular and Cellular Biology 26 7331-7341. (https://doi.org/10.1128/ MCB.00581-06)

Jia L, Berman BP, Jariwala U, Yan X, Cogan JP, Walters A, Chen T, Buchanan G, Frenkel B \& Coetzee GA 2008 Genomic androgen receptor-occupied regions with different functions, defined by histone acetylation, coregulators and transcriptional capacity. PLoS ONE 3 e3645. (https://doi.org/10.1371/journal.pone.0003645)

Jin L, Garcia J, Chan E, de la Cruz C, Segal E, Merchant M, Kharbanda S, Raisner R, Haverty PM, Modrusan Z, et al. 2017 Therapeutic targeting of the $\mathrm{CBP} / \mathrm{p} 300$ bromodomain blocks the growth of castration-resistant prostate cancer. Cancer Research 77 5564-5575. (https://doi.org/10.1158/0008-5472.CAN-17-0314)

Johnson DS, Mortazavi A, Myers RM \& Wold B 2007 Genome-wide mapping of in vivo protein-DNA interactions. Science $\mathbf{3 1 6}$ 1497-1502. (https://doi.org/10.1126/science.1141319)

Jones D, Noble M, Wedge SR, Robson CN \& Gaughan L 2017 Aurora A regulates expression of AR-V7 in models of castrate resistant prostate cancer. Scientific Reports 7 40957. (https://doi.org/10.1038/srep40957)

Jozwik KM, Chernukhin I, Serandour AA, Nagarajan S \& Carroll JS 2016 FOXA1 directs H3K4 monomethylation at enhancers via recruitment of the methyltransferase MLL3. Cell Reports 17 2715-2723. (https:// doi.org/10.1016/j.celrep.2016.11.028)

Kang Z, Pirskanen A, Jänne OA \& Palvimo JJ 2002 Involvement of proteasome in the dynamic assembly of the androgen receptor transcription complex. Journal of Biological Chemistry $27 \mathbf{7}$ 48366-48371. (https://doi.org/10.1074/jbc.M209074200)

Kang Z, Janne OA \& Palvimo JJ 2004 Coregulator recruitment and histone modifications in transcriptional regulation by the androgen receptor. Molecular Endocrinology 18 2633-2648. (https://doi. org/10.1210/me.2004-0245)

Khan MA, Walsh PC, Miller MC, Bales WD, Epstein JI, Mangold LA, Partin AW \& Veltri RW 2003 Quantitative alterations in nuclear structure predict prostate carcinoma distant metastasis and death in men with biochemical recurrence after radical prostatectomy. Cancer 98 2583-2591. (https://doi.org/10.1002/cncr.11852)

Kieffer-Kwon KR, Nimura K, Rao SSP, Xu J, Jung S, Pekowska A, Dose M, Stevens E, Mathe E, Dong P, et al. 2017 Myc regulates chromatin decompaction and nuclear architecture during B cell activation. Molecular Cell 67 566-578.e10. (https://doi.org/10.1016/j. molcel.2017.07.013)

Kim W \& Ryan CJ 2012 Androgen receptor directed therapies in castration-resistant metastatic prostate cancer. Current Treatment Options in Oncology 13 189-200. (https://doi.org/10.1007/s11864012-0188-2)

Kim J, Lee Y, Lu X, Song B, Fong KW, Cao Q, Licht JD, Zhao JC \& Yu J 2018 Polycomb- and methylation-independent roles of EZH2 as a transcription activator. Cell Reports 25 2808.e4-2820.e4. (https://doi. org/10.1016/j.celrep.2018.11.035)

Kinnaird A, Zhao S, Wellen KE \& Michelakis ED 2016 Metabolic control of epigenetics in cancer. Nature Reviews Cancer 16 694-707. (https:// doi.org/10.1038/nrc.2016.82)

Kivinummi K, Urbanucci A, Leinonen K, Tammela TLJ, Annala M, Isaacs WB, Bova GS, Nykter M \& Visakorpi T 2017 The expression of AURKA is androgen regulated in castration-resistant prostate cancer. Scientific Reports 7 17978. (https://doi.org/10.1038/s41598-017-18210-3)

Kleppe A, Albregtsen F, Vlatkovic L, Pradhan M, Nielsen B, Hveem TS, Askautrud HA, Kristensen GB, Nesbakken A, Trovik J, et al. 2018 Chromatin organisation and cancer prognosis: a pan-cancer study. Lancet Oncology 19 356-369. (https://doi.org/10.1016/S14702045(17)30899-9)

Koh CM, Bieberich CJ, Dang CV, Nelson WG, Yegnasubramanian S \& De Marzo AM 2010 MYC and prostate cancer. Genes and Cancer $\mathbf{1}$ 617-628. (https://doi.org/10.1177/1947601910379132)

Koo SJ, Fernandez-Montalvan AE, Badock V, Ott CJ, Holton SJ, von Ahsen O, Toedling J, Vittori S, Bradner JE \& Gorjanacz M 2016 ATAD2 is an epigenetic reader of newly synthesized histone marks during DNA replication. Oncotarget 7 70323-70335. (https://doi. org/10.18632/oncotarget.11855)

Kotaja N, Karvonen U, Janne OA \& Palvimo JJ 2002 PIAS proteins modulate transcription factors by functioning as SUMO-1 ligases. Molecular and Cellular Biology 22 5222-5234. (https;//doi. org/10.1128/MСВ.22.14.5222-5234.2002)

Kroon J, Puhr M, Buijs JT, van der Horst G, Hemmer DM, Marijt KA, Hwang MS, Masood M, Grimm S, Storm G, et al. 2016 Glucocorticoid receptor antagonism reverts docetaxel resistance in human prostate cancer. Endocrine-Related Cancer 23 35-45. (https:// doi.org/10.1530/ERC-15-0343)

Ku SY, Rosario S, Wang Y, Mu P, Seshadri M, Goodrich ZW, Goodrich MM, Labbé DP, Gomez EC, Wang J, et al. 2017 Rb1 and Trp53 cooperate to suppress prostate cancer lineage plasticity, metastasis, and antiandrogen resistance. Science 355 78-83. (https:// doi.org/10.1126/science.aah4199)

Kvale R, Myklebust TÅ, Engholm G, Heinavaara S, Wist E \& Moller B 2017 Prostate and breast cancer in four Nordic countries: a comparison of incidence and mortality trends across countries and age groups 1975-2013. International Journal of Cancer 141 2228-2242. (https://doi.org/10.1002/ijc.30924)

Längst G \& Manelyte L 2015 Chromatin remodelers: from function to dysfunction. Genes 6 299-324. (https://doi.org/10.3390/ genes6020299) https://erc.bioscientifica.com

https://doi.org/10.1530/ERC-18-0579 (c) 2019 Society for Endocrinology Published by Bioscientifica Ltd. Printed in Great Britain 
Latonen L, Afyounian E, Jylha A, Nattinen J, Aapola U, Annala M, Kivinummi KK, Tammela TTL, Beuerman RW, Uusitalo H, et al. 2018 Integrative proteomics in prostate cancer uncovers robustness against genomic and transcriptomic aberrations during disease progression. Nature Communications 9 1176. (https://doi.org/10.1038/ s41467-018-03573-6)

Lee TI \& Young RA 2013 Transcriptional regulation and its misregulation in disease. Cell 152 1237-1251. (https://doi.org/10.1016/j. cell.2013.02.014)

Lee SO, Huang C-K, Jie L \& Chang C 2013 Androgen receptor-regulated genes in prostate cancer initiation versus metastasis. In AndrogenResponsive Genes in Prostate Cancer: Regulation, Function and Clinical Applications. Ed. Z Wang. New York, NY, USA: Springer, pp. 155-176.

Lee JK, Phillips JW, Smith BA, Park JW, Stoyanova T, McCaffrey EF, Baertsch R, Sokolov A, Meyerowitz JG, Mathis C, et al. 2016 N-Myc drives neuroendocrine prostate cancer initiated from human prostate epithelial cells. Cancer Cell 29 536-547. (https://doi.org/10.1016/j. ccell.2016.03.001)

Lee AR, Gan Y, Tang Y \& Dong X 2018 A novel mechanism of SRRM4 in promoting neuroendocrine prostate cancer development via a pluripotency gene network. EBioMedicine 35 167-177. (https://doi. org/10.1016/j.ebiom.2018.08.011)

Li X, Egervari G, Wang Y, Berger SL \& Lu Z 2018 Regulation of chromatin and gene expression by metabolic enzymes and metabolites. Nature Reviews Molecular Cell Biology 19 563-578. (https://doi.org/10.1038/s41580-018-0029-7)

Liang Y, Ahmed M, Guo H, Soares F, Hua JT, Gao S, Lu C, Poon C, Han W, Langstein J, et al. 2017 LSD1-mediated epigenetic reprogramming drives CENPE expression and prostate cancer progression. Cancer Research 77 5479-5490. (https://doi. org/10.1158/0008-5472.CAN-17-0496)

Linja MJ, Porkka KP, Kang Z, Savinainen KJ, Janne OA, Tammela TL, Vessella RL, Palvimo JJ \& Visakorpi T 2004 Expression of androgen receptor coregulators in prostate cancer. Clinical Cancer Research 10 1032-1040. (https://doi.org/10.1158/1078-0432.CCR-0990-3)

Liu S, Kumari S, Hu Q, Senapati D, Venkadakrishnan VB, Wang D, DePriest AD, Schlanger SE, Ben-Salem S, Valenzuela MM, et al. 2017 A comprehensive analysis of coregulator recruitment, androgen receptor function and gene expression in prostate cancer. eLife $\mathbf{6}$ e28482. (https://doi.org/10.7554/eLife.28482)

Lu J, Lonergan PE, Nacusi LP, Wang L, Schmidt LJ, Sun Z, Van der Steen T, Boorjian SA, Kosari F, Vasmatzis G, et al. 2015 The cistrome and gene signature of androgen receptor splice variants in castration resistant prostate cancer cells. Journal of Urology 193 690-698. (https://doi.org/10.1016/j.juro.2014.08.043)

Lupien M, Eeckhoute J, Meyer CA, Wang Q, Zhang Y, Li W, Carroll JS, Liu XS \& Brown M 2008 FoxA1 translates epigenetic signatures into enhancer-driven lineage-specific transcription. Cell 132 958-970. (https://doi.org/10.1016/j.cell.2008.01.018)

Makova KD \& Hardison RC 2015 The effects of chromatin organization on variation in mutation rates in the genome. Nature Reviews Genetics 16 213-223. (https://doi.org/10.1038/nrg3890)

Mani RS, Tomlins SA, Callahan K, Ghosh A, Nyati MK, Varambally S, Palanisamy N \& Chinnaiyan AM 2009 Induced chromosomal proximity and gene fusions in prostate cancer. Science $\mathbf{3 2 6} 1230$. (https://doi.org/10.1126/science.1178124)

Massie CE, Lynch A, Ramos-Montoya A, Boren J, Stark R, Fazli L, Warren A, Scott H, Madhu B, Sharma N, et al. 2011 The androgen receptor fuels prostate cancer by regulating central metabolism and biosynthesis. EMBO Journal 30 2719-2733. (https://doi.org/10.1038/ emboj.2011.158)

Massie CE, Mills IG \& Lynch AG 2017 The importance of DNA methylation in prostate cancer development. Journal of Steroid Biochemistry and Molecular Biology 166 1-15. (https://doi. org/10.1016/j.jsbmb.2016.04.009)
Matsumoto T, Sakari M, Okada M, Yokoyama A, Takahashi S, Kouzmenko A \& Kato S 2013 The androgen receptor in health and disease. Annual Review of Physiology 75 201-224. (https://doi. org/10.1146/annurev-physiol-030212-183656)

McEwan IJ 2004 Molecular mechanisms of androgen receptor-mediated gene regulation: structure-function analysis of the AF-1 domain. Endocrine-Related Cancer 11 281-293. (https://doi.org/10.1677/ erc.0.0110281)

McNair C, Urbanucci A, Comstock CE, Augello MA, Goodwin JF, Launchbury R, Zhao SG, Schiewer MJ, Ertel A, Karnes J, et al. 2017 Cell cycle-coupled expansion of AR activity promotes cancer progression. Oncogene 36 1655-1668. (https://doi.org/10.1038/ onc.2016.334)

McNair C, Xu K, Mandigo AC, Benelli M, Leiby B, Rodrigues D, Lindberg J, Gronberg H, Crespo M, De Laere B, et al. 2018 Differential impact of RB status on E2F1 reprogramming in human cancer. Journal of Clinical Investigation 128 341-358. (https://doi. org/10.1172/JCI93566)

Medina PP \& Sanchez-Cespedes M 2008 Involvement of the chromatinremodeling factor BRG1/SMARCA4 in human cancer. Epigenetics 3 64-68. (https://doi.org/10.4161/epi.3.2.6153)

Mills IG 2014 Maintaining and reprogramming genomic androgen receptor activity in prostate cancer. Nature Reviews Cancer 14 187-198. (https://doi.org/10.1038/nrc3678)

Mohammad OS, Nyquist MD, Schweizer MT, Balk SP, Corey E, Plymate S, Nelson PS \& Mostaghel EA 2017 Supraphysiologic testosterone therapy in the treatment of prostate cancer: models, mechanisms and questions. Cancers 9 166. (https://doi.org/10.3390/cancers9120166)

Morozumi Y, Boussouar F, Tan M, Chaikuad A, Jamshidikia M, Colak G, He H, Nie L, Petosa C, de Dieuleveult M, et al. 2016 Atad2 is a generalist facilitator of chromatin dynamics in embryonic stem cells. Journal of Molecular Cell Biology 8 349-362. (https://doi.org/10.1093/ jmcb/mjv060)

Mosquera JM, Beltran H, Park K, MacDonald TY, Robinson BD, Tagawa ST, Perner S, Bismar TA, Erbersdobler A, Dhir R, et al. 2013 Concurrent AURKA and MYCN gene amplifications are harbingers of lethal treatment-related neuroendocrine prostate cancer. Neoplasia 15 1-10. (https://doi.org/10.1593/neo.121550)

Mu P, Zhang Z, Benelli M, Karthaus WR, Hoover E, Chen CC, Wongvipat J, Ku SY, Gao D, Cao Z, et al. 2017 SOX2 promotes lineage plasticity and antiandrogen resistance in TP53- and RB1deficient prostate cancer. Science 355 84-88. (https://doi.org/10.1126/ science.aah4307)

Ni M, Chen Y, Fei T, Li D, Lim E, Liu XS \& Brown M 2013 Amplitude modulation of androgen signaling by c-MYC. Genes and Development 27 734-748. (https://doi.org/10.1101/gad.209569.112)

Nupponen NN, Kakkola L, Koivisto P \& Visakorpi T 1998 Genetic alterations in hormone-refractory recurrent prostate carcinomas. American Journal of Pathology 153 141-148. (https://doi.org/10.1016/ S0002-9440(10)65554-X)

O'Neill LP \& Turner BM 1996 Immunoprecipitation of chromatin. Methods in Enzymology 274 189-197. (https://doi.org/10.1016/S00766879(96)74017-X)

Paakinaho V, Presman DM, Ball DA, Johnson TA, Schiltz RL, Levitt P, Mazza D, Morisaki T, Karpova TS \& Hager GL 2017 Single-molecule analysis of steroid receptor and cofactor action in living cells. Nature Communications 8 15896. (https://doi.org/10.1038/ncomms15896)

Park JW, Lee JK, Sheu KM, Wang L, Balanis NG, Nguyen K, Smith BA, Cheng C, Tsai BL, Cheng D, et al. 2018 Reprogramming normal human epithelial tissues to a common, lethal neuroendocrine cancer lineage. Science 362 91-95. (https://doi.org/10.1126/science.aat5749)

Pawar A, Gollavilli PN, Wang S \& Asangani IA 2018 Resistance to BET inhibitor leads to alternative therapeutic vulnerabilities in castrationresistant prostate cancer. Cell Reports 22 2236-2245. (https://doi. org/10.1016/j.celrep.2018.02.011) https://erc.bioscientifica.com

https://doi.org/10.1530/ERC-18-0579 (c) 2019 Society for Endocrinology Published by Bioscientifica Ltd. Printed in Great Britain 
Pellakuru LG, Iwata T, Gurel B, Schultz D, Hicks J, Bethel C, Yegnasubramanian S \& De Marzo AM 2012 Global levels of H3K27me3 track with differentiation in vivo and are deregulated by MYC in prostate cancer. American Journal of Pathology 181 560-569. (https://doi.org/10.1016/j.ajpath.2012.04.021)

Perry AS, Watson RW, Lawler M \& Hollywood D 2010 The epigenome as a therapeutic target in prostate cancer. Nature Reviews Urology 7 668-680. (https://doi.org/10.1038/nrurol.2010.185)

Pihlajamaa P, Sahu B \& Janne OA 2015 Determinants of receptor- and tissue-specific actions in androgen signaling. Endocrine Reviews 36 357-384. (https://doi.org/10.1210/er.2015-1034)

Pomerantz MM, Li F, Takeda DY, Lenci R, Chonkar A, Chabot M, Cejas P, Vazquez F, Cook J, Shivdasani RA, et al. 2015 The androgen receptor cistrome is extensively reprogrammed in human prostate tumorigenesis. Nature Genetics 47 1346-1351. (https://doi. org/10.1038/ng.3419)

Puhr M, Hoefer J, Eigentler A, Ploner C, Handle F, Schaefer G, Kroon J, Leo A, Heidegger I, Eder I, et al. 2018 The glucocorticoid receptor is a key player for prostate cancer cell survival and a target for improved antiandrogen therapy. Clinical Cancer Research 24 927-938. (https://doi.org/10.1158/1078-0432.CCR-17-0989)

Quigley DA, Dang HX, Zhao SG, Lloyd P, Aggarwal R, Alumkal JJ, Foye A, Kothari V, Perry MD, Bailey AM, et al. 2018 Genomic hallmarks and structural variation in metastatic prostate cancer. Cell 175 758-769.e759. (https://doi.org/10.1016/j.cell.2018.10.019)

Rathert P, Roth M, Neumann T, Muerdter F, Roe JS, Muhar M, Deswal S, Cerny-Reiterer S, Peter B, Jude J, et al. 2015 Transcriptional plasticity promotes primary and acquired resistance to BET inhibition. Nature 525 543-547. (https://doi.org/10.1038/nature14898)

Ratnam M, Patki M, Gonit M \& Trumbly R 2013 Mechanisms of AREindependent gene activation by the androgen receptor in prostate cancer cells: potential targets for better intervention strategies. In Androgen-Responsive Genes in Prostate Cancer: Regulation, Function and Clinical Applications. Ed. Z Wang. New York, NY, USA: Springer, pp. 85-100.

Rehman Y \& Rosenberg JE 2012 Abiraterone acetate: oral androgen biosynthesis inhibitor for treatment of castration-resistant prostate cancer. Drug Design, Development and Therapy 6 13-18. (https://doi. org/10.2147/DDDT.S15850)

Rhee HS \& Pugh BF 2012 ChIP-exo method for identifying genomic location of DNA-binding proteins with near-single-nucleotide accuracy. Current Protocols in Molecular Biology 100 21.24.1-21.24.14. (https://doi.org/10.1002/0471142727.mb2124s100)

Robinson JL, Macarthur S, Ross-Innes CS, Tilley WD, Neal DE, Mills IG \& Carroll JS 2011 Androgen receptor driven transcription in molecular apocrine breast cancer is mediated by FoxA1. EMBO Journal 30 3019-3027. (https://doi.org/10.1038/emboj.2011.216)

Robinson JLL, Hickey TE, Warren AY, Vowler SL, Carroll T, Lamb AD, Papoutsoglou N, Neal DE, Tilley WD \& Carroll JS 2014 Elevated levels of FOXA1 facilitate androgen receptor chromatin binding resulting in a CRPC-like phenotype. Oncogene 33 5666-5674. (https://doi.org/10.1038/onc.2013.508)

Robinson D, Van Allen Eliezer M, Wu Y-M, Schultz N, Lonigro RJ, Mosquera J-M, Montgomery B, Taplin M-E, Pritchard CC, Attard G, et al. 2015 Integrative clinical genomics of advanced prostate cancer. Cell 161 1215-1228. (https://doi.org/10.1016/j.cell.2015.05.001)

Rodriguez-Bravo V, Carceles-Cordon M, Hoshida Y, Cordon-Cardo C, Galsky MD \& Domingo-Domenech J 2017 The role of GATA2 in lethal prostate cancer aggressiveness. Nature Reviews Urology 14 38-48. (https://doi.org/10.1038/nrurol.2016.225)

Rubin MA, Maher CA \& Chinnaiyan AM 2011 Common gene rearrangements in prostate cancer. Journal of Clinical Oncology 29 3659-3668. (https://doi.org/10.1200/JCO.2011.35.1916)

Rudnizky S, Bavly A, Malik O, Pnueli L, Melamed P \& Kaplan A 2016 H2A.Z controls the stability and mobility of nucleosomes to regulate expression of the LH genes. Nature Communications 7 12958. (https:// doi.org/10.1038/ncomms12958)

Ruggero K, Farran-Matas S, Martinez-Tebar A \& Aytes A 2018 Epigenetic regulation in prostate cancer progression. Current Molecular Biology Reports 4 101-115. (https://doi.org/10.1007/s40610-018-0095-9)

Rytinki MM, Kaikkonen S, Sutinen P \& Palvimo JJ 2011 Analysis of androgen receptor SUMOylation. Methods in Molecular Biology 776 183-197. (https://doi.org/10.1007/978-1-61779-243-4_12)

Sahu B, Laakso M, Ovaska K, Mirtti T, Lundin J, Rannikko A, Sankila A, Turunen JP, Lundin M, Konsti J, et al. 2011 Dual role of FoxA1 in androgen receptor binding to chromatin, androgen signalling and prostate cancer. EMBO Journal 30 3962-3976. (https://doi. org/10.1038/emboj.2011.328)

Sahu B, Pihlajamaa P, Dubois V, Kerkhofs S, Claessens F \& Janne OA 2014 Androgen receptor uses relaxed response element stringency for selective chromatin binding and transcriptional regulation in vivo. Nucleic Acids Research 42 4230-4240. (https://doi.org/10.1093/ nar/gkt1401)

Schmidt R \& Plath K 2012 The roles of the reprogramming factors Oct4, Sox 2 and Klf4 in resetting the somatic cell epigenome during induced pluripotent stem cell generation. Genome Biology $\mathbf{1 3}$ 251-251. (https://doi.org/10.1186/gb-2012-13-10-251)

Schvartzman JM, Thompson CB \& Finley LWS 2018 Metabolic regulation of chromatin modifications and gene expression. Journal of Cell Biology 217 2247-2259. (https://doi.org/10.1083/ jcb.201803061)

Sehrawat A, Gao L, Wang Y, Bankhead A, McWeeney SK, King CJ, Schwartzman J, Urrutia J, Bisson WH, Coleman DJ, et al. 2018 LSD1 activates a lethal prostate cancer gene network independently of its demethylase function. PNAS 115 E4179-E4188. (https://doi. org/10.1073/pnas.1719168115)

Seligson DB, Horvath S, Shi T, Yu H, Tze S, Grunstein M \& Kurdistani SK 2005 Global histone modification patterns predict risk of prostate cancer recurrence. Nature 435 1262-1266. (https://doi.org/10.1038/ nature03672)

Seligson DB, Horvath S, McBrian MA, Mah V, Yu H, Tze S, Wang Q, Chia D, Goodglick L \& Kurdistani SK 2009 Global levels of histone modifications predict prognosis in different cancers. American Journal of Pathology 174 1619-1628. (https://doi.org/10.2353/ajpath.2009.080874)

Shah N, Wang P, Wongvipat J, Karthaus WR, Abida W, Armenia J, Rockowitz S, Drier Y, Bernstein BE, Long HW, et al. 2017 Regulation of the glucocorticoid receptor via a BET-dependent enhancer drives antiandrogen resistance in prostate cancer. eLife 6 e27861. (https:// doi.org/10.7554/eLife.27861)

Sharma NL, Massie CE, Ramos-Montoya A, Zecchini V, Scott HE, Lamb AD, MacArthur S, Stark R, Warren AY, Mills IG, et al. 2013 The androgen receptor induces a distinct transcriptional program in castration-resistant prostate cancer in man. Cancer Cell 23 35-47. (https://doi.org/10.1016/j.ccr.2012.11.010)

Sharp A, Coleman I, Yuan W, Sprenger C, Dolling D, Rodrigues DN, Russo JW, Figueiredo I, Bertan C, Seed G, et al. 2019 Androgen receptor splice variant-7 expression emerges with castration resistance in prostate cancer. Journal of Clinical Investigation 129 192-208. (https://doi.org/10.1172/JCI122819)

Song L, Zhang Z, Grasfeder LL, Boyle AP, Giresi PG, Lee BK, Sheffield NC, Graf S, Huss M, Keefe D, et al. 2011 Open chromatin defined by DNaseI and FAIRE identifies regulatory elements that shape cell-type identity. Genome Research 21 1757-1767. (https://doi. org/10.1101/gr.121541.111)

Stelloo S, Nevedomskaya E, van der Poel HG, de Jong J, van Leenders GJ, Jenster G, Wessels LF, Bergman AM \& Zwart W 2015 Androgen receptor profiling predicts prostate cancer outcome. EMBO Molecular Medicine 7 1450-1464. (https://doi.org/10.15252/emmm.201505424)

Stelloo S, Nevedomskaya E, Kim Y, Hoekman L, Bleijerveld OB, Mirza T, Wessels LFA, van Weerden WM, Altelaar AFM, Bergman AM, et al. https://erc.bioscientifica.com

https://doi.org/10.1530/ERC-18-0579 (c) 2019 Society for Endocrinology Published by Bioscientifica Ltd. Printed in Great Britain 
2018 Endogenous androgen receptor proteomic profiling reveals genomic subcomplex involved in prostate tumorigenesis. Oncogene 37 313-322. (https://doi.org/10.1038/onc.2017.330)

Sur I \& Taipale J 2016 The role of enhancers in cancer. Nature Reviews Cancer 16 483-493. (https://doi.org/10.1038/nrc.2016.62)

Surface LE, Fields PA, Subramanian V, Behmer R, Udeshi N, Peach SE, Jaffe JD \& Boyer LA 2016 H2A.Z.1 Mono-ubiquitylation antagonizes BRD2 to maintain poised chromatin in ESCs. Cell Reports $\mathbf{1 4}$ 1142-1155. (https://doi.org/10.1016/j.celrep.2015.12.100)

Taberlay PC, Statham AL, Kelly TK, Clark SJ \& Jones PA 2014 Reconfiguration of nucleosome-depleted regions at distal regulatory elements accompanies DNA methylation of enhancers and insulators in cancer. Genome Research 24 1421-1432. (https://doi.org/10.1101/ gr.163485.113)

Taberlay PC, Achinger-Kawecka J, Lun ATL, Buske FA, Sabir K, Gould CM, Zotenko E, Bert SA, Giles KA, Bauer DC, et al. 2016 Three-dimensional disorganization of the cancer genome occurs coincident with long-range genetic and epigenetic alterations. Genome Research 26 719-731. (https://doi.org/10.1101/gr.201517.115)

Taipale J 2018 The chromatin of cancer. Science 362 401-402. (https:// doi.org/10.1126/science.aav3494)

Takahashi K, Tanabe K, Ohnuki M, Narita M, Ichisaka T, Tomoda K \& Yamanaka S 2007 Induction of pluripotent stem cells from adult human fibroblasts by defined factors. Cell 131 861-872. (https://doi. org/10.1016/j.cell.2007.11.019)

Takayama K 2018 Epigenetic regulation by androgen receptor in prostate cancer. OBM Genetics 2 e047.

Taslim C, Chen Z, Huang K, Huang TH, Wang Q \& Lin S 2012 Integrated analysis identifies a class of androgen-responsive genes regulated by short combinatorial long-range mechanism facilitated by CTCF. Nucleic Acids Research $\mathbf{4 0}$ 4754-4764. (https://doi. org/10.1093/nar/gks139)

Taylor BS, Schultz N, Hieronymus H, Gopalan A, Xiao Y, Carver BS, Arora VK, Kaushik P, Cerami E, Reva B, et al. 2010 Integrative genomic profiling of human prostate cancer. Cancer Cell 18 11-22. (https://doi.org/10.1016/j.ccr.2010.05.026)

Teply BA \& Antonarakis ES 2016 Novel mechanism-based therapeutics for androgen axis blockade in castration-resistant prostate cancer. Current Opinion in Endocrinology, Diabetes, and Obesity 23 279-290. (https://doi.org/10.1097/MED.0000000000000254)

Teply BA, Wang H, Luber B, Sullivan R, Rifkind I, Bruns A, Spitz A, DeCarli M, Sinibaldi V, Pratz CF, et al. 2018 Bipolar androgen therapy in men with metastatic castration-resistant prostate cancer after progression on enzalutamide: an open-label, phase 2, multicohort study. Lancet Oncology 19 76-86. (https://doi. org/10.1016/S1470-2045(17)30906-3)

Tewari AK, Yardimci GG, Shibata Y, Sheffield NC, Song L, Taylor BS, Georgiev SG, Coetzee GA, Ohler U, Furey TS, et al. 2012 Chromatin accessibility reveals insights into androgen receptor activation and transcriptional specificity. Genome Biology 13 R88. (https://doi. org/10.1186/gb-2012-13-10-r88)

Timp W \& Feinberg AP 2013 Cancer as a dysregulated epigenome allowing cellular growth advantage at the expense of the host. Nature Reviews Cancer 13 497-510. (https://doi.org/10.1038/nrc3486)

Tomlins SA, Rhodes DR, Perner S, Dhanasekaran SM, Mehra R, Sun XW Varambally S, Cao X, Tchinda J, Kuefer R, et al. 2005 Recurrent fusion of TMPRSS2 and ETS transcription factor genes in prostate cancer. Science 310 644-648. (https://doi.org/10.1126/ science.1117679)

Totten RS, Heinemann MW, Hudson PB, Sproul EE \& Stout AP 1953 Microscopic differential diagnosis of latent carcinoma of prostate. A.M.A. Archives of Pathology 55 131-141.

Urbanucci A \& Mills IG 2018 Bromodomain-containing proteins in prostate cancer. Molecular and Cellular Endocrinology 462 31-40. (https://doi.org/10.1016/j.mce.2017.06.007)
Urbanucci A, Waltering KK, Suikki HE, Helenius MA \& Visakorpi T 2008 Androgen regulation of the androgen receptor coregulators. BMC Cancer 8 219. (https://doi.org/10.1186/1471-2407-8-219)

Urbanucci A, Marttila S, Janne OA \& Visakorpi T 2012a Androgen receptor overexpression alters binding dynamics of the receptor to chromatin and chromatin structure. Prostate 72 1223-1232. (https:// doi.org/10.1002/pros.22473)

Urbanucci A, Sahu B, Seppala J, Larjo A, Latonen LM, Waltering KK, Tammela TL, Vessella RL, Lahdesmaki H, Janne OA, et al. 2012b Overexpression of androgen receptor enhances the binding of the receptor to the chromatin in prostate cancer. Oncogene $\mathbf{3 1}$ 2153-2163. (https://doi.org/10.1038/onc.2011.401)

Urbanucci A, Waltering K, Mills I \& Visakorpi T 2013 The effect of AR overexpression on androgen signaling in prostate cancer. In Androgen-Responsive Genes in Prostate Cancer. Ed. Z Wang. New York, NY, USA: Springer, pp. 187-200.

Urbanucci A, Barfeld SJ, Kytola V, Itkonen HM, Coleman IM, Vodak D, Sjoblom L, Sheng X, Tolonen T, Minner S, et al. 2017 Androgen receptor deregulation drives bromodomain-mediated chromatin alterations in prostate cancer. Cell Reports 19 2045-2059. (https:// doi.org/10.1016/j.celrep.2017.05.049)

Valdes-Mora F, Gould CM, Colino-Sanguino Y, Qu W, Song JZ, Taylor KM, Buske FA, Statham AL, Nair SS, Armstrong NJ, et al. 2017 Acetylated histone variant H2A.Z is involved in the activation of neo-enhancers in prostate cancer. Nature Communications 81346. (https://doi.org/10.1038/s41467-017-01393-8)

Waltering KK, Helenius MA, Sahu B, Manni V, Linja MJ, Janne OA \& Visakorpi T 2009 Increased expression of androgen receptor sensitizes prostate cancer cells to low levels of androgens. Cancer Research 69 8141-8149. (https://doi.org/10.1158/0008-5472.CAN-090919)

Waltering KK, Porkka KP, Jalava SE, Urbanucci A, Kohonen PJ, Latonen LM, Kallioniemi OP, Jenster G \& Visakorpi T 2011 Androgen regulation of micro-RNAs in prostate cancer. Prostate $\mathbf{7 1}$ 604-614. (https://doi.org/10.1002/pros.21276)

Waltering KK, Urbanucci A \& Visakorpi T 2012 Androgen receptor (AR) aberrations in castration-resistant prostate cancer. Molecular and Cellular Endocrinology 360 38-43. (https://doi.org/10.1016/j. mce.2011.12.019)

Wang D, Garcia-Bassets I, Benner C, Li W, Su X, Zhou Y, Qiu J, Liu W, Kaikkonen MU, Ohgi KA, et al. 2011 Reprogramming transcription by distinct classes of enhancers functionally defined by eRNA. Nature 474 390-394. (https://doi.org/10.1038/nature10006)

Wang Q, Li W, Liu XS, Carroll JS, Janne OA, Keeton EK, Chinnaiyan AM, Pienta KJ \& Brown M 2007 A hierarchical network of transcription factors governs androgen receptor-dependent prostate cancer growth. Molecular Cell 27380 -392. (https://doi. org/10.1016/j.molcel.2007.05.041)

Wang Q, Li W, Zhang Y, Yuan X, Xu K, Yu J, Chen Z, Beroukhim R, Wang H, Lupien M, et al. 2009 Androgen receptor regulates a distinct transcription program in androgen-independent prostate cancer. Cell 138245 -256. (https://doi.org/10.1016/j. cell.2009.04.056)

Wang G, Zhao D, Spring DJ \& DePinho RA 2018a Genetics and biology of prostate cancer. Genes and Development 32 1105-1140. (https:// doi.org/10.1101/gad.315739.118)

Wang S, Singh SK, Katika MR, Lopez-Aviles S \& Hurtado A $2018 b$ High throughput chemical screening reveals multiple regulatory proteins on FOXA1 in breast cancer cell lines. International Journal of Molecular Sciences 19 4123. (https://doi.org/10.3390/ijms19124123)

Watson PA, Chen YF, Balbas MD, Wongvipat J, Socci ND, Viale A, Kim K \& Sawyers CL 2010 Constitutively active androgen receptor splice variants expressed in castration-resistant prostate cancer require fulllength androgen receptor. PNAS 107 16759-16765. (https://doi. org/10.1073/pnas.1012443107) https://erc bioscientifica com

https://doi.org/10.1530/ERC-18-0579
(C) 2019 Society for Endocrinology Published by Bioscientifica Ltd. Printed in Great Britain 
Watson PA, Arora VK \& Sawyers CL 2015 Emerging mechanisms of resistance to androgen receptor inhibitors in prostate cancer. Nature Reviews Cancer 15 701-711. (https://doi.org/10.1038/nrc4016)

Weischenfeldt J, Simon R, Feuerbach L, Schlangen K, Weichenhan D, Minner S, Wuttig D, Warnatz HJ, Stehr H, Rausch T, et al. 2013 Integrative genomic analyses reveal an androgen-driven somatic alteration landscape in early-onset prostate cancer. Cancer Cell $\mathbf{2 3}$ 159-170. (https://doi.org/10.1016/j.ccr.2013.01.002)

Welti J, Sharp A, Yuan W, Dolling DI, Nava Rodrigues D, Figueiredo I, Gil V, Neeb A, Clarke M, Seed G, et al. 2018 Targeting bromodomain and extra-terminal (BET) family proteins in castration resistant prostate cancer (CRPC). Clinical Cancer Research 24 3149-3162. (https://doi.org/10.1158/1078-0432.CCR-17-3571)

Wyce A, Degenhardt Y, Bai Y, Le B, Korenchuk S, Crouthamel M-C, McHugh C, Vessella R, Creasy C, Tummino P, et al. 2013 Inhibition of BET bromodomain proteins as a therapeutic approach in prostate cancer. Oncotarget 4 2419-2429. (https://doi.org/10.18632/ oncotarget.1572)

Xu K, Wu ZJ, Groner AC, He HH, Cai C, Lis RT, Wu X, Stack EC, Loda M, Liu T, et al. 2012 EZH2 oncogenic activity in castrationresistant prostate cancer cells is Polycomb-independent. Science 338 1465-1469. (https://doi.org/10.1126/science.1227604)

Xu Q, Liu X, Zhu S, Hu X, Niu H, Zhang X, Zhu D, Nesa EU, Tian K \& Yuan H 2018 Hyper-acetylation contributes to the sensitivity of chemo-resistant prostate cancer cells to histone deacetylase inhibitor trichostatin A. Journal of Cellular and Molecular Medicine 22 1909-1922. (https://doi.org/10.1111/jcmm.13475)

Yaffe E \& Tanay A 2011 Probabilistic modeling of Hi-C contact maps eliminates systematic biases to characterize global chromosomal architecture. Nature Genetics 43 1059-1065. (https://doi.org/10.1038/ ng.947)

Ylipaa A, Kivinummi K, Kohvakka A, Annala M, Latonen L, Scaravilli M, Kartasalo K, Leppanen SP, Karakurt S, Seppala J, et al. 2015 Transcriptome sequencing reveals PCAT5 as a novel ERG-regulated long non-coding RNA in prostate cancer. Cancer Research $\mathbf{7 5}$ 4026-4031. (https://doi.org/10.1158/0008-5472.CAN-15-0217)
Yu J, Yu J, Mani RS, Cao Q, Brenner CJ, Cao X, Wang X, Wu L, Li J, $\mathrm{Hu} \mathrm{M}$, et al. 2010 An integrated network of androgen receptor, polycomb, and TMPRSS2-ERG gene fusions in prostate cancer progression. Cancer Cell 17443 -454. (https://doi.org/10.1016/j. ccr.2010.03.018)

Yun M, Wu J, Workman JL \& Li B 2011 Readers of histone modifications. Cell Research 21 564-578. (https://doi.org/10.1038/cr.2011.42)

Zehir A, Benayed R, Shah RH, Syed A, Middha S, Kim HR, Srinivasan P, Gao J, Chakravarty D, Devlin SM, et al. 2017 Mutational landscape of metastatic cancer revealed from prospective clinical sequencing of 10,000 patients. Nature Medicine 23 703-713. (https://doi. org/10.1038/nm.4333)

Zhang C, Wang L, Wu D, Chen H, Chen Z, Thomas-Ahner JM, Zynger DL, Eeckhoute J, Yu J, Luo J, et al. 2011 Definition of a FoxA1 cistrome that is crucial for G1 to S-phase cell-cycle transit in castration-resistant prostate cancer. Cancer Research 71 6738-6748. (https://doi.org/10.1158/0008-5472.CAN-11-1882)

Zhao JC, Fong KW, Jin HJ, Yang YA, Kim J \& Yu J 2016 FOXA1 acts upstream of GATA2 and AR in hormonal regulation of gene expression. Oncogene 35 4335-4344. (https://doi.org/10.1038/ onc.2015.496)

Zhou LX, Li T, Huang YR, Sha JJ, Sun P \& Li D 2010 Application of histone modification in the risk prediction of the biochemical recurrence after radical prostatectomy. Asian Journal of Andrology $\mathbf{1 2}$ 171-179. (https://doi.org/10.1038/aja.2009.81)

Zou JX, Guo L, Revenko AS, Tepper CG, Gemo AT, Kung HJ \& Chen HW 2009 Androgen-induced coactivator ANCCA mediates specific androgen receptor signaling in prostate cancer. Cancer Research 69 3339-3346. (https://doi.org/10.1158/0008-5472. CAN-08-3440)

Zuber V, Bettella F, Witoelar A, PRACTICAL Consortium, CRUK GWAS, BCAC Consortium, TRICL Consortium, Andreassen OA, Mills IG \& Urbanucci A 2017 Bromodomain protein 4 discriminates tissuespecific super-enhancers containing disease-specific susceptibility loci in prostate and breast cancer. BMC Genomics 18 270. (https://doi. org/10.1186/s12864-017-3620-y)

Received in final form 13 February 2019

Accepted 15 February 2019 (c) 2019 Society for Endocrinology Published by Bioscientifica Ltd. Printed in Great Britain 